Document downloaded from:

http://hdl.handle.net/10251/52147

This paper must be cited as:

González Espín, FJ.; Figueres Amorós, E.; Garcerá Sanfeliú, G. (2012). An adaptive synchronous-reference-frame phase-locked loop for power quality improvement in a polluted utility grid. IEEE Transactions on Industrial Electronics. 59(6):2718-2731. doi:10.1109/TIE.2011.2166236.

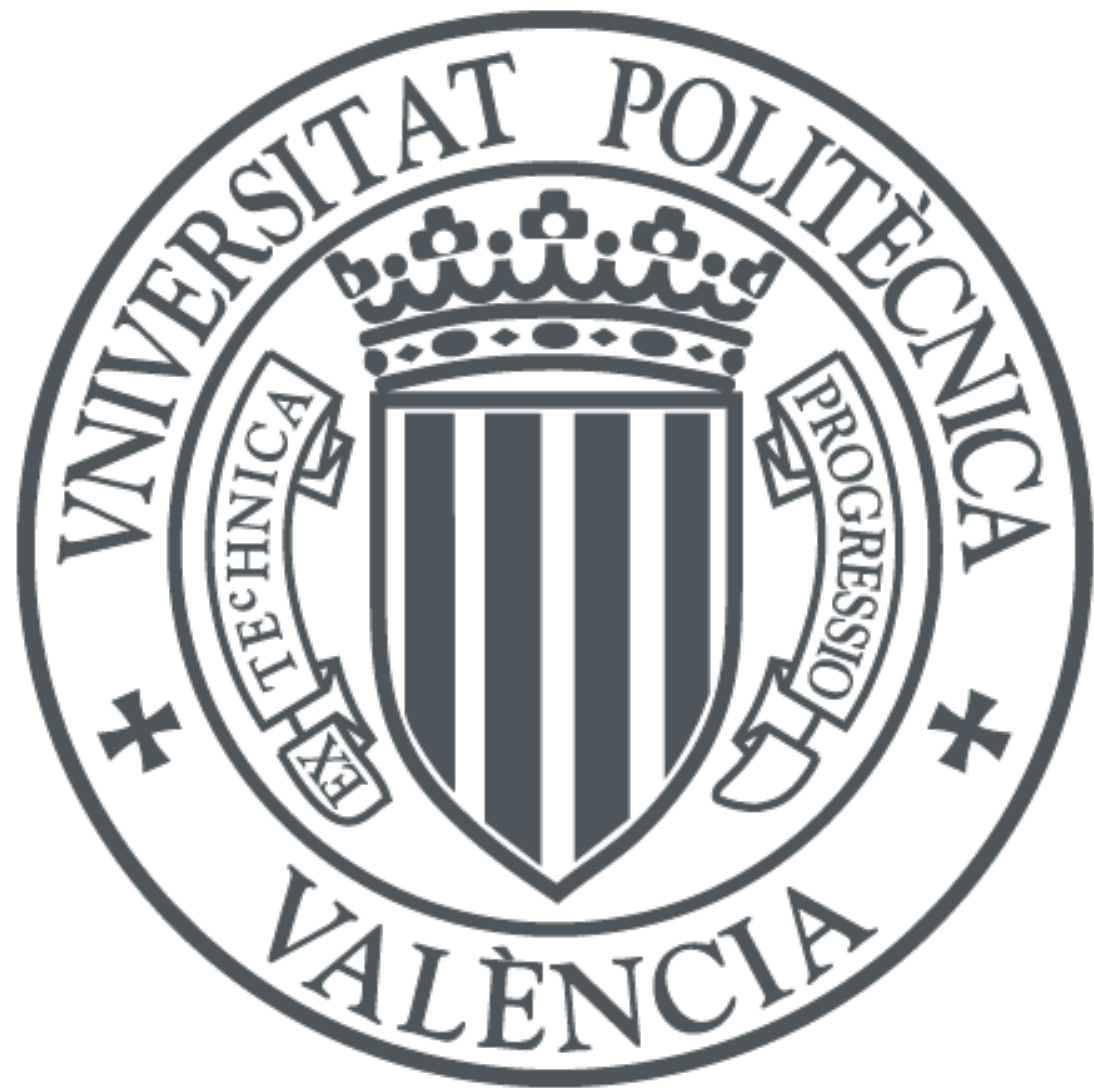

The final publication is available at

http://dx.doi.org/10.1109/TIE.2011.2166236

Copyright Institute of Electrical and Electronics Engineers (IEEE)

Additional Information

Si el (C) es de IEEE cuando se deposite una versión de autor hay que poner el siguiente texto en "descripción": "(C) (C) 20xx IEEE. Personal use of this material is permitted. Permission from IEEE must be obtained for all other uses, in any current or future media, including reprinting/republishing this material for advertising or promotional purposes, creating new collective works, for resale or redistribution to servers or lists, or reuse of any copyrighted component of this work in other works." 


\section{An Adaptive Synchronous Reference Frame Phase-Locked Loop for Power Quality Improvement in a Polluted Utility Grid}

\begin{abstract}
The proper operation of the grid-connected power electronics converters usually needs using some kind of synchronization technique in order to estimate the phase of the grid voltage. The performance of this synchronization technique is of a great importance when trying to improve the quality of the consumed or delivered electric power. The synchronous reference frame phase-locked loop (SRF-PLL) synchronization algorithm has been widely used in recent years due to its ease of operation and robust behavior. However, the estimated phase can have a considerable amount of unwanted ripple if the grid voltage disturbances (e.g. harmonic distortion and unbalance) are not properly rejected. The aim of this paper is to propose an adaptive SRF-PLL which is able to strongly reject the aforementioned disturbances even if the fundamental frequency of the grid voltage varies. This synchronization method will allow the designer to easily upgrade an existing SRF-PLL, thus improving the performance of working power converters. This is accomplished by using several adaptive Infinite Impulse Response (IIR) notch filters, implemented by means of an inherently stable Schur-lattice structure. Besides the stability properties, this structure accomplished the most important topics required to be programed into the commonly used fixed point DSPs (i.e. high mapping precision, low round-off accumulation, suppression of quantization limit cycle oscillations). The proposed adaptive SRF-PLL has been tested by programing the algorithm into the fixed-point digital signal processor TI TMS320F2812. The obtained experimental results show up that the proposed synchronization method highly rejects the undesired harmonics, even if the fundamental harmonic frequency of a highly polluted grid voltage abruptly varies.
\end{abstract}

Index Terms - Phase locked loop, power system harmonics, power grids, power quality, three-phase electric power, adaptive signal processing, adaptive filters, lattice filters.

\section{INTRODUCTION}

$\mathrm{T}$ he advent of renewable energy s ources in conjunction with the distributed generation in a microgrid environment is rapidly changing the el ectric generation paradigm [1], [2]. Traditional centralized power plants will be working together with $\mathrm{d}$ istributed ge nerators a nd e ven with a lternative e nergy storage systems a s the e lectric vehicle [3], [4]. Most of the technological challenges involving this new scenario are being solved $t$ hrough $t$ echnical s olutions ba sed on $t$ he po wer electronics control field.

One important issue to be solved when managing the power delivered by di stributed $g$ enerators, $\mathrm{i}$ s t he co rrect synchronization with the electric grid [5-7]. Information about the instantaneous phase of the grid voltage is needed to obtain the reference of the current delivered by the power electronics converter [8-11]. This implies that the quality of the injected power is highly related with the accuracy of this information. Despite the fact that several techniques could be used to carry out the synchronization with the grid, the s tate o $\mathrm{ft}$ he art suggests the use of the Synchronous Reference Frame PhaseLocked Loop (SRF-PLL) to estimate the instantaneous $g$ rid voltage $p$ hase [12-15]. T he SRF-PLL needs the three-phase grid voltage to be projected from the Natural Reference Frame (NRF) i nto t he $\mathrm{S}$ ynchronous $\mathrm{R}$ eference $\mathrm{F}$ rame ( $\mathrm{SRF}$ ). A simple cl osed-loop c ontrol s cheme b y means of a proportional-integral $(\mathrm{PI})$ regulator can be used to estimate the electric grid voltage phase [16].

Several studies have been made that allow to affirm that the SRF-PLL gives an accurate phase grid estimation if the electric grid is not polluted (i.e. the grid voltage is balanced and $\mathrm{i} t \mathrm{~d}$ oes $\mathrm{n}$ ot co ntain harmonics $\mathrm{d}$ ifferent from the fundamental). However, this PLL inserts a certain a mount of distortion when the point of common coupling (PCC) of the power el ectronics co nverter is p olluted [16-18]. T aking into account that the estimated phase is used for synthesizing the reference o $\mathrm{ft}$ he $\mathrm{i}$ njected current, the es timated $\mathrm{p}$ hase imperfections deteriorate the quality of the power delivered to the utility grid. In many cases, this could n ot be accep table, since the current standards and $r$ ecommendations $r$ egarding distributed $\mathrm{r}$ esources 1 imit $\mathrm{t}$ he maximum $\mathrm{c}$ urrent $\mathrm{d}$ istortion [19], [20].

In order to avoid the grid disturbances to affect the phase estimation, a car efully choice of the tuning parameters of the PI re gulator has t o be done, so th at a good di sturbance rejection is obtained [21]. However, this a pproach makes the SRF-PLL extremely slow if a good rejection of the unbalance disturbance is required. In [22], a feedforward action is used to improve $\mathrm{t}$ he $\mathrm{ph}$ ase e stimation s peed, which i s i ntended t o compensate for the poor transient behavior introduced by the low-pass filter used to attenuate the utility grid disturbances. Moreover, i n [23], [24] several methods ar e p resented that 
allow to $\mathrm{r}$ eject $\mathrm{u}$ ndesired $\mathrm{r}$ ipple i $\mathrm{nt}$ he e stimated $\mathrm{p}$ hase. Nevertheless, $t$ he be havior of $t$ he proposed $m$ ethod i s not studied when a variation in the grid frequency takes place (e.g. in a microgrid working in the islanding mode [25], [26]).

In order to take into account the grid frequency variation, [27] and [28] propose a s imple structure of adaptive resonant filters. This technique allows rejecting the variable frequency harmonics that could appear in the estimated phase. Although it allows obtaining a first approach to the solution of the grid frequency variation problem, it should be noted that the stability o $\mathrm{ft}$ he a daptive method is $\mathrm{n}$ ot well $\mathrm{s}$ tudied. The stability $\mathrm{s}$ tudy is $\mathrm{m}$ andatory since the pr oposed $\mathrm{f}$ ilters a re implemented by means of a direct form infinite impulse response (IIR) structure, which in turn could be unstable if not correctly adjusted. Moreover, the proposed filters need a reference $t$ o $t$ rack $t$ he grid $f$ requency variation. As $t$ his reference i s o btained b y means o f t he i nitially $\mathrm{p}$ olluted estimated frequency, the obtained IIR filter will start swinging until it b ecomes unstable. In [29], a l ead co mpensator is introduced which claims to obtain a fast tracking of the grid voltage $\mathrm{p}$ hase. In order to ad apt the ce nter frequency of the lead compensator, the frequency estimated by the SRF-PLL is used. However, a low-pass filter with low cut-off frequency is introduced to avoid oscillations and instability in steady-state. Therefore, the bandwidth of the SRF-PLL is highly limited by this low-pass filter, instead of by the loop-gain of the control loop. Furthermore, the stability of the lead compensator when the coefficients are real-time varied is not studied, so that the stability of the whole system could not be a ssured under a ll circumstances.

There ar e o ther methods which as sure s tability in $t$ he adaptive process. In [30] it is proposed a method based on a multiple s ynchronous $r$ eference $f$ rame $t \mathrm{o} d$ etect $t$ he $p$ ositive and the negative sequence grid voltage components. In [31], a method to detect the fundamental frequency of the utility grid regardless of the presence of unbalance or harmonic distortion is shown. However, the complexity of the estimation process increase notably respect to the SRF-PLL algorithm.

The aim of this paper is to propose a phase estimator based on the well-known SRF-PLL, which has a high rejection of the disturbances introduced by the voltage unbalance and by the voltage harmonic distortion, regardless of the grid frequency variation. The system is based on the adaptive filtering of the harmonics that appear on the grid voltage projection into the $\mathrm{SRF}$, when the utility grid is unbalanced and distorted. On one hand, $t$ he ad aptive $n$ ature of the filtering $p$ rocess makes the

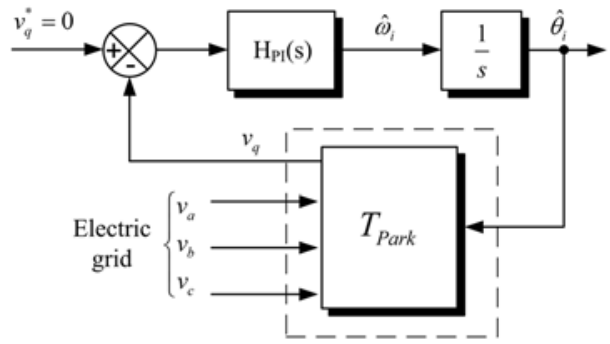

(a) rejection in sensitive to the grid frequency variation. On the other hand, the Schur-lattice IIR structure used to implement the $\mathrm{f}$ ilter $\mathrm{s}$ tage makes $\mathrm{t}$ he $\mathrm{s}$ tability o $\mathrm{ft}$ he $\mathrm{p}$ hase es timator independent $\mathrm{o} f \mathrm{t}$ he ad aptive $\mathrm{p}$ rocess. In fact, $\mathrm{t}$ he filter is inherently stable, an d d oes $n$ eed $n$ either an y r eference to be properly $t$ uned nor a dded filtering $s$ tage $t o$ a void $s$ winging. Moreover, the proposed IIR structure makes this technique a suitable choice for fixed point DSPs, or even for cheap fixed point ds PICs, due to its low round-off noise a nd its e ase to remove $\mathrm{q}$ uantization li mit $\mathrm{c}$ ycles. These $\mathrm{p}$ roperties a llow obtaining two major benefits [32]; the mapping of the control loop transfer functions poles and zeros are more precise, and the $q$ uantization li mit c ycles $\mathrm{c}$ an $\mathrm{b}$ e e asily $\mathrm{r}$ emoved, th us avoiding $\mathrm{s}$ winging $\mathrm{i} \mathrm{nt}$ he a daptive pr ocess. Furthermore, existing SRF-PLL source co des in working power converters could be e asily updated i $\mathrm{n}$ or der $\mathrm{t}$ o obt ain the a daptive rejection feature.

The paper is organized as follows. In Section II, a model of the $\mathrm{c}$ onventional SRF-PLL $\mathrm{i}$ s s hown a long with $\mathrm{t}$ he conventional PI control scheme. Furthermore, the behavior of the SRF-PLL is studied when the voltage grid is polluted. In Section III, a first approach to cancel out the harmonics in the estimated phase when the voltage grid is polluted is s hown. This technique i $\mathrm{s} b$ ased o $\mathrm{n}$ IIR $\mathrm{n}$ otch $\mathrm{f}$ ilters $\mathrm{t}$ uned at fixed frequencies. S ection IV p resents a $\mathrm{n}$ a daptive I IR notch filter algorithm that is able to ad aptively tune its center frequency, without the ne ed of a given reference. The inherently s table operation of th is filter is a lso $\mathrm{p}$ robed in th is $\mathrm{s}$ ection. $\mathrm{T}$ his algorithm a llows the SRF-PLL $t$ o s uccessfully $r$ eject the undesired harmonics even if the voltage grid frequency varies. In $\mathrm{S}$ ection $\mathrm{V}$, e xperimental $\mathrm{r}$ esults are $\mathrm{s}$ hown. $\mathrm{F}$ inally, an Appendix is a dded with the pseudo-code to be added to the SRF-PLL, so that it becomes adaptive.

\section{THE SRF-PLL}

\section{A. Modeling and Control of the SRF-PLL}

The conventional S RF-PLL is ba sed on the projection of the utility g rid voltage shown by (1) from the NRF into the SRF. Fig. 1(a) shows the basic block diagram of the SRF-PLL. The PI regulator described by (2) and an integrator along with the no n-linear r otation matrix s hown by (3) are u sed in the closed loop control scheme.

In o rder to a djust th e P I r egulator, a s mall s ignal lin ear model of the SRF-PLL can be derived [16], thus obtaining the block diagram depicted in Fig. 1(b). In this figure, $p$ is the grid disturbance signal, $v_{q}$ is the grid voltage $q$ axis projection into

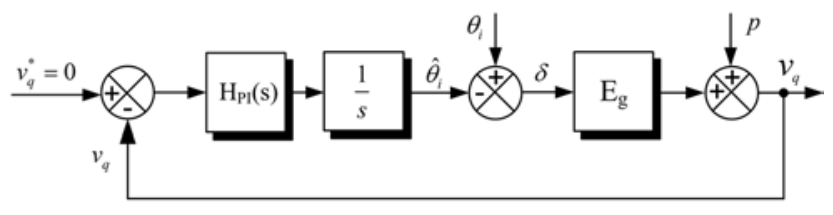

Fig. 1. (a) Basic block diagram and (b) small signal block diagram of a SRF-PLL 


$$
\begin{aligned}
& \vec{v}_{g}(t)=\left[\begin{array}{c}
v_{a}(t) \\
v_{b}(t) \\
v_{c}(t)
\end{array}\right]=V_{1} \cdot\left[\begin{array}{c}
\cos \left(\theta_{i}\right) \\
\cos \left(\theta_{i}-\frac{2 \pi}{3}\right) \\
\cos \left(\theta_{i}+\frac{2 \pi}{3}\right)
\end{array}\right] \\
& H_{P I}(s)=-K_{p} \cdot\left(1+\frac{K_{i}}{s}\right) \\
& T_{\text {park }}=\sqrt{\frac{2}{3}}\left[\begin{array}{ccc}
\cos \left(\hat{\theta}_{i}\right) & \cos \left(\hat{\theta}_{i}-\frac{2 \pi}{3}\right) & \cos \left(\hat{\theta}_{i}+\frac{2 \pi}{3}\right) \\
-\sin \left(\hat{\theta}_{i}\right) & -\sin \left(\hat{\theta}_{i}-\frac{2 \pi}{3}\right) & -\sin \left(\hat{\theta}_{i}+\frac{2 \pi}{3}\right) \\
\frac{1}{\sqrt{2}} & \frac{1}{\sqrt{2}} & \frac{1}{\sqrt{2}}
\end{array}\right]
\end{aligned}
$$

the SRF, $v_{q}^{*}$ is the reference of this projection, $\theta_{i}$ and $\hat{\theta}_{i}$ are the grid phase and the estimated grid phase respectively, and $\delta$ is the error between the actual and the estimated grid phase. This model allows to derive the open loop gain expressed by (4) and the transfer function between the estimated phase, $\hat{\theta}_{i}$, and the grid disturbances, $p$, depicted in (5). These transfer functions are used to study the stability and the effect of the grid disturbances on $t$ he es timated $\mathrm{p}$ hase respectively. It should be c onsidered that $\mathrm{t}$ he $\mathrm{r}$ otation matrix gain, $E_{g}$, is characterized by (6), where $V_{1}$ is the amplitude of the $\mathrm{g}$ rid voltage fundamental harmonic in the NRF.

$$
\begin{gathered}
T_{P L L}(s)=-E_{g} \cdot H_{P I}(s) \cdot \frac{1}{s} \\
G_{\theta_{-} p}(s)=\frac{\hat{\theta}_{i}}{p}=\frac{1}{E_{g}} \frac{T_{P L L}(s)}{1+T_{P L L}(s)} \\
E_{g}=\sqrt{\frac{3}{2}} V_{1}
\end{gathered}
$$

\section{B. The SRF-PLL applied to a Polluted Grid}

The el ectric $g$ rid $\mathrm{i} s \mathrm{u}$ sually $\mathrm{r}$ epresented $\mathrm{b}$ y $\mathrm{t}$ he $\mathrm{i}$ deal expression shown by (1). H owever, the vo ltage a t t he P CC often contains harmonics other than the fundamental, as well as a certain amount of unbalance. To take these non-idealities into account (7) could be used instead.

It is worth pointing out that the most usual non-linear loads connected to the $\mathrm{PCC}$, ar e three-phase full b ridge c ontrolled and no $n$-controlled 1 ine $f$ requency $r$ ectifiers. $T$ herefore, the even and the triplen harmonics are considered to be zero [33], [34]. By a pplying the transformation matrix (3) to (7), a nd taking into account that (8) holds in the steady-state, (9) can be derived, where $E_{p u}, \phi_{p u}$ and $\delta$ are defined in (10), (11) and (12) respectively [16], [18], [30].
By c arefully e xamining (9), it can b e co ncluded that the absence of unbalance $(\beta=\gamma=0)$ and harmonic distortion in the grid voltage results in the expression for the $q$ term, $v_{q}=E_{g} \delta$. This expression can be derived from Fig. 1(b) by considering the $\mathrm{d}$ isturbance $\mathrm{t}$ o b e zer o $(p=0)$. Therefore, $\mathrm{i} \mathrm{t}$ can $\mathrm{b}$ e concluded that the disturbance introduced in the SRF by the unbalance a nd the distortion of $t$ he grid voltage can $b$ e expressed by (13) and (14) respectively.

$$
\vec{v}_{g}=\left[\begin{array}{c}
V_{1} \cos \left(\theta_{i}\right)-V_{5} \cos \left(5 \theta_{i}\right)+V_{7} \cos \left(7 \theta_{i}\right)-V_{11} \cos \left(11 \theta_{i}\right)+\ldots \\
(1+\beta) \cdot\left(V_{1} \cos \left(\theta_{i}-\frac{2 \pi}{3}\right)-V_{5} \cos \left(5\left(\theta_{i}-\frac{2 \pi}{3}\right)\right)+\ldots\right) \\
(1+\gamma) \cdot\left(V_{1} \cos \left(\theta_{i}+\frac{2 \pi}{3}\right)-V_{5} \cos \left(5\left(\theta_{i}+\frac{2 \pi}{3}\right)\right)+\ldots\right)
\end{array}\right]
$$

$$
\begin{aligned}
& v_{q}=E_{g} \delta \cdot\left(\frac{3+\gamma+\beta}{3}\right)+E_{g} E_{p u} \cos \left(2 \theta_{i}-\phi_{p u}\right)+ \\
& +\sqrt{\frac{3}{2}}\left(V_{5}+V_{7}\right) \cdot \cos \left(6 \theta_{i}+\frac{\pi}{2}\right)+\sqrt{\frac{3}{2}}\left(V_{11}+V_{13}\right) \cdot \cos \left(12 \theta_{i}+\frac{\pi}{2}\right)+\ldots
\end{aligned}
$$

$$
\begin{gathered}
E_{p u}=\sqrt{\left(\frac{(\gamma-\beta)}{2 \sqrt{3}}\right)^{2}+\left(\frac{(\gamma+\beta)}{6}\right)^{2}} \\
\phi_{p u}=\tan ^{-1}\left(\frac{\sqrt{3}}{3} \frac{(\gamma+\beta)}{(\gamma-\beta)}\right) \\
\delta=\theta_{i}-\hat{\theta}_{i}
\end{gathered}
$$

$$
P_{q u}=E_{g} \delta \cdot\left(\frac{3+\gamma+\beta}{3}\right)+E_{g} E_{p u} \cos \left(2 \theta_{i}-\phi_{p u}\right)
$$

$$
\begin{aligned}
& P_{q d}=\sqrt{\frac{3}{2}}\left(V_{5}+V_{7}\right) \cdot \cos \left(6 \theta_{i}+\frac{\pi}{2}\right)+ \\
& +\sqrt{\frac{3}{2}}\left(V_{11}+V_{13}\right) \cdot \cos \left(12 \theta_{i}+\frac{\pi}{2}\right)+\ldots
\end{aligned}
$$

An important issue that should be taken into account is that the disturbance in the $q$ term of the SRF projection pollutes the phase es timated $b$ y the SRF-PLL. I ndeed, $b$ y $t$ aking i nto account (12) and that $v_{q}=v_{q}^{*}=0$ in the steady state, (15) is obtained by equating (9) to zero and solving for $\hat{\theta}_{i}$.

$$
\begin{aligned}
& \hat{\theta}_{i}=\theta_{i}+\frac{3}{3+\gamma+\beta} E_{p u} \cos \left(2 \theta_{i}-\phi_{p u}\right)+\frac{\left(V_{5}+V_{7}\right)}{V_{1}} \cdot \cos \left(6 \theta_{i}+\frac{\pi}{2}\right)+ \\
& +\frac{\left(V_{11}+V_{13}\right)}{V_{1}} \cdot \cos \left(12 \theta_{i}+\frac{\pi}{2}\right)+\ldots
\end{aligned}
$$


From (15) it is concluded that the e stimated $\mathrm{p}$ hase has a certain a mount of $\mathrm{u}$ ndesired $\mathrm{r}$ ipple if the $\mathrm{u}$ tility grid is $\mathrm{n}$ ot ideal, and the SRF-PLL is not correctly designed (i.e. if the undesired harmonics are not filtered out).

In Fig. 2 it is d epicted the Bode plot of the di sturbance attenuation transfer function shown in (5), when the SRF-PLL is designed according to the parameters shown in Table I. $K_{p}$ and $K_{i}$ are the p roportional an $\mathrm{d}$ the integral $\mathrm{g}$ ains of the PI regulator, $f_{s}$ is the sampling frequency of the discretized SRF$\mathrm{PLL}, \beta_{V}$ is the sensing gain previous to the ADC stage, $P M$ is the phase margin and $G M$ is the ga in margin. The B ode plot reveals $t$ hat $\mathrm{t}$ he harmonics $\mathrm{d}$ ue $\mathrm{t}$ ot he $\mathrm{P} \mathrm{CC}$ voltage disturbances ( i.e. unbalance a nd harmonic $\mathrm{d}$ istortion) are poorly rejected. In fact, the harmonic due to the PCC voltage unbalance at $2 f_{i}=100 \mathrm{~Hz}$ is a mplified, where $f_{i}$ is the grid voltage fundamental frequency.

The po or r ejection be havior of the proposed S RF-PLL is clearly $\mathrm{n}$ oticeable $\mathrm{f}$ rom $\mathrm{t}$ he simulation $\mathrm{s}$ hown in Fig. 3(b), where the voltage at the PCC has been programmed according to Table II. As ex pected, the es timated phase, $\hat{\theta}_{i}$, and the $q$ term of the SRF projection, $v_{q}$, contains the harmonics shown by (15) and (9) respectively. However, the estimated phase is synchronized with $v_{a}(t)$, and the $q$ term of the SRF projection is zero when an ideal utility grid (i.e. the utility grid shown by (1)) is used to feed the input of the phase estimator, as it $c$ an be seen in Fig. 3(a).

Although the bandwidth of the system could be reduced to obtain $\mathrm{a} b$ etter harmonic $\mathrm{r}$ ejection, $\mathrm{t}$ he $\mathrm{s}$ ettling time of $\mathrm{t}$ he SRF-PLL would be too slow if a good attenuation has to be obtained (e.g. a $B W=35 \mathrm{~Hz}$ allows an attenuation of only $-4.42 d B)$.

\section{Selective Filtering TeChNiQue}

In o rder t o s electively $r$ emove $t$ he $h$ armonics $d$ ue $t$ o the disturbances, a set of $n$ second order notch filters can be used in cascade as shown in Fig. 4, each of those filters removing one of $\mathrm{t}$ he $\mathrm{u}$ ndesired $\mathrm{h}$ armonics which ap pear i $\mathrm{n} v_{q}$, $\mathrm{t}$ hus allowing to obtain $\hat{\theta}_{i}=\theta_{i}$ from (15).

A widely used digital filter structure is the IIR second order
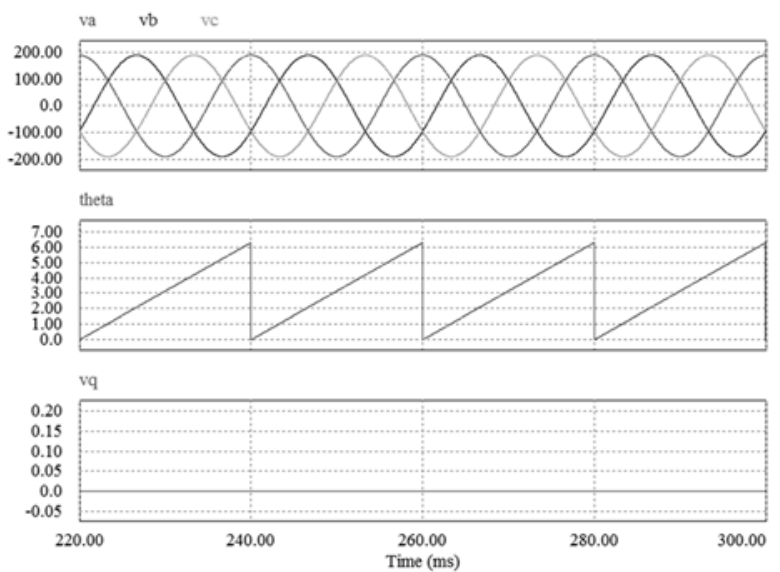

(a)

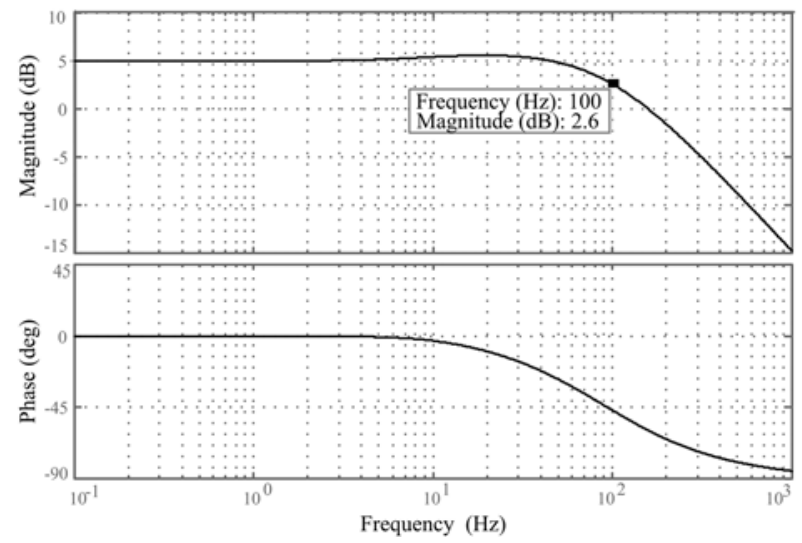

Fig. 2. Attenuation of the disturbances contained in the $q$ term of the SRF-PLL.

TABLE I

PARAMETERS OF THE SRF-PLL AND OF THE IDEAL UTILITY GRID

\begin{tabular}{cc}
\hline \hline Parameter & Value \\
\hline$V_{1}$ & $188 \mathrm{~V}$ \\
$f_{i}$ & $50 \mathrm{~Hz}$ \\
$K_{p}$ & 1114 \\
$K_{i}$ & 63 \\
$f_{s}$ & $16000 \mathrm{~Hz}$ \\
$\beta_{V}$ & $2.5^{-3} \cdot 10^{-3}$ \\
$P M-f_{c}$ & $82.3^{\circ}$ at $99.7 \mathrm{~Hz}$ \\
$G M-f$ & $47.1 \mathrm{~dB}$ at $8000 \mathrm{~Hz}$
\end{tabular}

TABLE II

PARAMETERS OF THE POLLUTEd UTILITY GRID

\begin{tabular}{cc}
\hline \hline Parameter & Value \\
\hline$V_{1}$ & $188 \mathrm{~V}$ \\
$V_{5}=0.1 V_{1}$ & $18.8 \mathrm{~V}$ \\
$V_{7}=0.07 V_{1}$ & $13.2 \mathrm{~V}$ \\
$V_{11}=0.05 V_{1}$ & $8.5 \mathrm{~V}$ \\
$V_{13}=0.04 V_{1}$ & $7.2 \mathrm{~V}$ \\
$\beta$ & -0.1 \\
$\gamma$ & 0.3
\end{tabular}
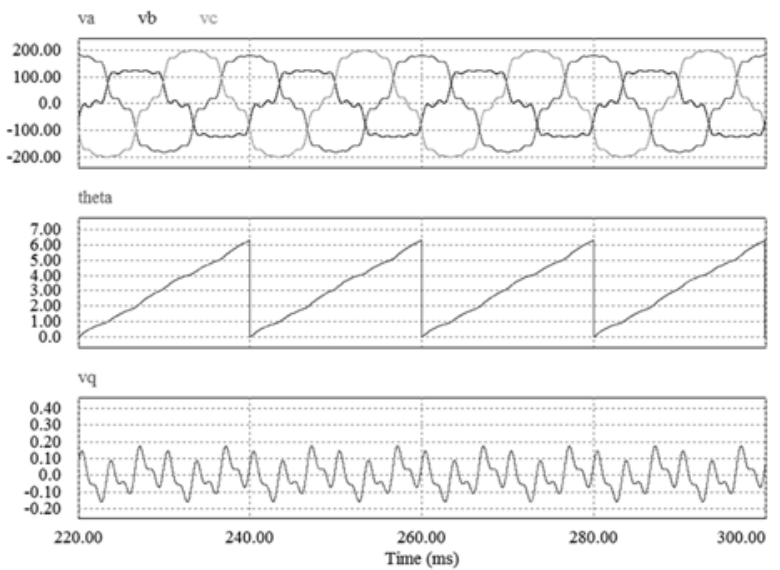

(b)

Fig. 3. Three-phase electric grid voltages (top), phase estimation of a SRF-PLL (middle) and $v_{q}$ signal (bottom) in a (a) non-distorted and non-unbalanced electric grid and (b) distorted and unbalanced electric grid. 


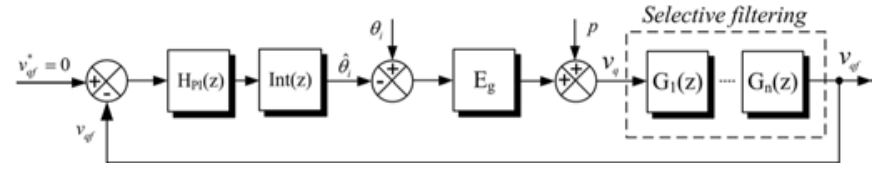

Fig. 4. Small signal block diagram of a SRF-PLL with $v_{q}$ signal selective filtering.

filter shown by (16), where the tuning parameters $a_{n}$ and $\rho_{n}$ are used $\mathrm{t} o$ set the $\mathrm{n}$ ormalized cen ter frequency, $\omega_{n}$, a nd the normalized $\mathrm{b}$ andwidth of $\mathrm{t}$ he $\mathrm{n}$ otch filter, $B W_{n}$, respectively, by using (17) and (18) [35-37]. The z-plane root locus and the Bode plot o $\mathrm{ft}$ he $\mathrm{f}$ ilter $\mathrm{f}$ or a f ixed no tching frequency of $\omega_{n}=2 \pi 100 \mathrm{rad} / \mathrm{s}$ and a sampling frequency of $f_{s}=16000 \mathrm{~Hz}$, are shown in Fig. 5(a) and in Fig. 5(b), respectively.

The use of the proposed filters modifies both the open loop gain, $T_{P L L}$, a nd the disturbance at tenuation of the $v_{q}$ signal, $G_{\theta, p}, \mathrm{~s}$ o th at (4) turns i nto (19), a nd (5) into (20). $G_{1}(z) \cdot \ldots \cdot G_{n}(z)$ are the transfer functions product of the $n$ notch filters used to filter out the disturbances. Note that (19) and (20) are discrete versions of (4) and (5) adding the discrete notch filters, where $\operatorname{Int}(\mathrm{z})$ is a discrete integrator.

$$
\begin{gathered}
G_{n}(z)=\frac{1+a_{n} z^{-1}+z^{-2}}{1+\rho_{n} a_{n} z^{-1}+\rho_{n}^{2} z^{-2}}, \quad-2<a_{n}<2 \\
\omega_{n}=\cos ^{-1}\left(-a_{n} / 2\right) \mathrm{rad} \\
B W_{n}=\pi\left(1-\rho_{n}\right) \mathrm{rad} \\
T_{P L L}^{\prime}(z)=-E_{g} \cdot H_{P I}(z) \cdot G_{1}(z) \cdot \ldots \cdot G_{n}(z) \cdot \operatorname{Int}(z) \\
G_{\theta_{-} p}^{\prime}(z)=\frac{1}{E_{g}} \frac{T_{P L L}^{\prime}(z)}{1+T_{P L L}^{\prime}(z)}
\end{gathered}
$$

The most important disturbances are those related with the PCC vo ltage $u$ nbalance a nd the fifth, s eventh, e leventh a nd thirteenth PCC NRF voltage harmonics [33], [34]. Therefore it is possible to use only three notch filters in the SRF, so that the disturbances described in (13) and (14) are removed

It is worth pointing out that the use of the notch filters in the closed loop control of the SRF-PLL i ntroduces new constraints when designing the PI regulator. The phase margin depends on the bandwidth of the notch filter, because the low frequency phase delay of a notch is higher the greater its

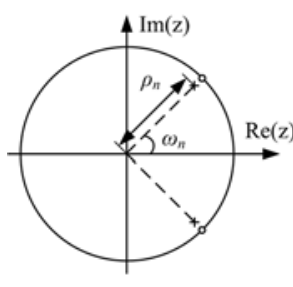

(a)

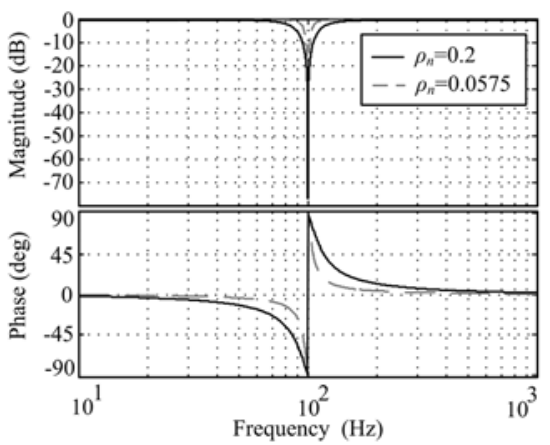

(b)
Fig. 5. Digital second order notch filter (a) root locus and (b) Bode plot. bandwidth, a s i t is d epicted in Fig. 5(b). Taking this i nto account, a n ew SRF-PLL which includes the notch filters can be designed according to the parameters shown in Table III.

The Bode plot of the disturbance rejection transfer function with notches, $G_{\theta p}^{\prime}(z)$, is shown in Fig. 6. The notch filters allow the S RF-PLL to co rrectly r eject the s econd, s ixth and twelfth harmonics, since they provide an attenuation of nearly $-50 \mathrm{~dB}$. However, if $\mathrm{t}$ here is a variation of the P CC voltage frequency, the at tenuation will g reatly decrease (e.g. a $-6 \%$ $\mathrm{PCC}$ voltage frequency variation will $\mathrm{c}$ ause the harmonics to be at tenuated only by $-3.85 \mathrm{~dB}$ ). A s it would be de sirable to have a co nstant at tenuation $r$ egardless of a $p$ ossible P CC voltage frequency variation, a t echnique for adaptive filtering of the disturbances is presented below.

\section{ADAPTIVE FILTERING}

The s elective filtering o $\mathrm{f}$ the harmonics $\mathrm{d}$ ue $\mathrm{t}$ o $\mathrm{t}$ he disturbance at the PCC voltage allows the SRF-PLL to obtain a co rrect es timation o $\mathrm{ft}$ he $\mathrm{p}$ hase. $\mathrm{H}$ owever, when $\mathrm{t}$ he frequency o $\mathrm{ft}$ he $\mathrm{P} \mathrm{CC}$ voltage va ries, $\mathrm{t}$ he highly s elective notch $\mathrm{f}$ ilters $\mathrm{d}$ o $\mathrm{n}$ ot correctly work, because $\mathrm{t}$ he $\mathrm{n}$ otch frequencies, $\omega_{n}$, are fixed.

In $\mathrm{o}$ rder $\mathrm{t} \mathrm{o}$ ad apt $\mathrm{t}$ he $\mathrm{n}$ otch frequency $\mathrm{o} \mathrm{ft}$ he filters according to the PCC voltage fundamental frequency, a finite impulse re sponse (F IR) o $\mathrm{r}$ i nfinite i mpulse re sponse (IIR ) adaptive notch filter can be used instead [37], [38].

TABLE III

PARAMETERS OF THE SELECTIVE FILTERING SRF-PLL

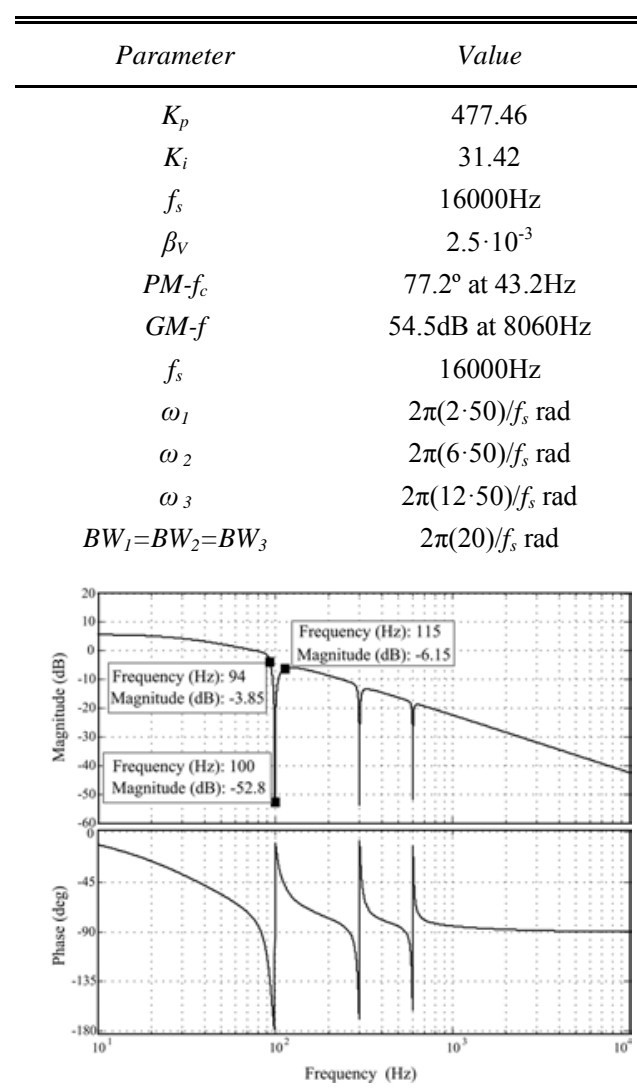

Fig. 6. Attenuation of the disturbances contained in the $v_{q}$ signal when using the selective filters. 
The adaptive $\mathrm{f}$ ilters ar $\mathrm{e} b$ ased o $\mathrm{n} t$ he use of a $\mathrm{r}$ ecursive algorithm to find the Wiener solution of an error surface that could be time variant (e.g. a surface dependent on the varying frequency of $\mathrm{t}$ he $\mathrm{P} \mathrm{CC}$ vo ltage). Although there ar e s everal methods $\mathrm{t}$ hat $\mathrm{c}$ ould $\mathrm{b}$ e us ed $\mathrm{t}$ o i mplement $\mathrm{t}$ he $\mathrm{r}$ ecursive algorithm, the most widely used is the Least Mean Squares (LMS) algorithm [39-43]. This method is intended to find the parameters o $\mathrm{ft}$ he function $\hat{H}(z)$ defined i $\mathrm{n}$ (21) that minimizes the quadratic error of the function defined in (22), where $H(z)$ is the transfer function of a given plant and $\zeta(z)$ is a disturbance signal statistically i ndependent of $\mathrm{t}$ he i nput signal, $u(z)$.

$$
\begin{gathered}
\hat{H}(z)=\frac{B(z)}{A(z)}=\frac{b_{0}+b_{1} z^{-1}+\cdots+b_{M} z^{-M}}{1+a_{1} z^{-1}+\cdots+a_{M} z^{-M}} \\
e(z)=y(z)-\hat{y}(z)=[H(z)-\hat{H}(z)] u(z)+\zeta(z)
\end{gathered}
$$

Although this method provides a good performance when applied to a FIR filter, an unstable filter could be obtained if it is used along with a direct form type IIR filter, since the poles of $t$ he $d$ iscrete transfer function ar e $n$ ot co nstrained t $o$ lay inside the unity circle [35], [36]. Although a FIR filter could be used to obtain an adaptive notch filter, the computational burden and the need of a given reference signal for the filter to work properly, makes this t opology le ss a ttractive th an the equivalent adaptive notch IIR filter. As it will be shown later, the IIR filter does not need a reference signal to cancel out the undesired $\mathrm{h}$ armonics. Furthermore, a second o rder I IR filter suffices to achieve this goal, while a higher order FIR filter is necessary to obtain the same filtering behavior, th us incrementing the computational burden [44]. In order to find a stable a daptive notch I IR filter, the la ttice structure a nd the gradient adaptive lattice algorithm is presented next.

\section{A. The Schur-Lattice IIR structure}

The Schur-lattice IIR structure is based on the Schur recursion depicted in Fig. 7(a), which carries out the rotation over $t$ he $t$ ransfer $f$ unctions involving $t$ he filtering process expressed in (23), where (24) applies.

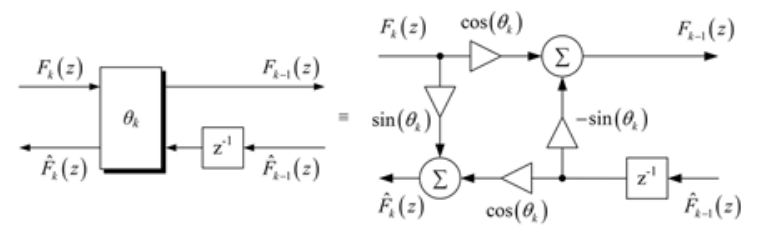

(a)

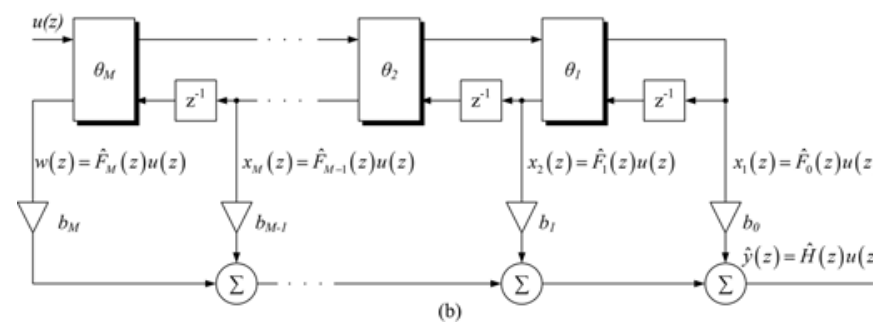

Fig. 7. (a) Schur recursion and (b) Mth order Schur-Lattice IIR filter.

$$
\begin{gathered}
{\left[\begin{array}{c}
F_{k-1}(z) \\
\hat{F}_{k}(z)
\end{array}\right]=\left[\begin{array}{cc}
\cos \left(\theta_{k}\right) & -\sin \left(\theta_{k}\right) \\
\sin \left(\theta_{k}\right) & \cos \left(\theta_{k}\right)
\end{array}\right]\left[\begin{array}{c}
F_{k}(z) \\
z^{-1} \hat{F}_{k-1}(z)
\end{array}\right]} \\
F_{k}(z) \triangleq D_{k}(z) / D_{M}(z), \quad \hat{F}_{k}(z) \triangleq \hat{D}_{k}(z) / D_{M}(z) \\
\hat{H}(z)=\sum_{k=0}^{M} b_{k} \hat{F}_{k}(z)
\end{gathered}
$$

Fig. 7(b) depicts a $M$ th order I IR filter i mplemented by means of the Schur recursion, whose transfer function can be expressed by (25). This structure is also known as the tapped state la ttice form, a nd it $\mathrm{h}$ as many $\mathrm{d}$ esirable $\mathrm{p}$ roperties $\mathrm{f}$ or fixed coefficient digital filtering [32]:

- The s tructure is in herently li mited to $r$ ealizing s table and cau sal filters. This means that the ad aptation process cannot result in an unstable filter.

- All the i nternal nodes ar e i nherently scaled in the $l_{2}$ sense ( also kno wn a st he E uclidean no rm). This property assures that the same Q-format could be used to program the filter, so that precision is not lost in the filtering process.

- Round-off noise acc umulation in the state vector loop is inherently low irrespective of the poles of the filter. In this regard, the mapping of the pol es and zeros is more $\mathrm{p}$ recise no matter the position of the pol es and zeros. $\mathrm{T}$ his $\mathrm{p}$ roperty $\mathrm{i} s$ very $\mathrm{i}$ nteresting $\mathrm{i} \mathrm{nl}$ owfrequency signal high-frequency sampling.

- Quantization li mit c ycles due to q uantization can be easily suppressed.

It should be noted that these properties allow obtaining a more e ffective filtering with le ss $r$ ipple $d$ ue to the a daptive process than in previously proposed adaptive methods.

\section{B. Stability of the Schur-Lattice IIR structure}

It is well $\mathrm{k}$ nown $\mathrm{t}$ hat th e proposed Schur-lattice I IR structure i s i nherently s table [32], [45], [46]. I ndeed, t his property c ould be probed by u sing the S chur-Cohn s tability test [47], which states that a function $f_{0}(z)$ is bounded real iff (if and only if) (i) $\left|f_{0}(0)\right|<1$ and (ii) the function $f_{1}(z)$ defined by (26) is bounded real. The function $f_{1}(z)$ could be tested in $\mathrm{t}$ he $\mathrm{s}$ ame $\mathrm{w}$ ay, $\mathrm{t}$ hus obtaining the sequence o $\mathrm{f}$ functions $f_{0}(z), f_{1}(z), \ldots, f_{M}(z)=1$. By calculating the sequence of numbers $f_{0}(0), f_{1}(0), \ldots, f_{M-1}(0)$ (i.e. the Schur parameters), the $\mathrm{S}$ chur-Cohn stability te st establishes $\mathrm{t}$ hat $f_{0}(z)$ is bounded real iff all the Schur parameters are smaller than one.

$$
f_{1}(z)=z^{-1} \frac{f_{0}(z)-f_{0}(0)}{1-f_{0}(z) f_{0}(0)}
$$

This te st $\mathrm{c}$ ould $\mathrm{b}$ e a pplied to th e tr ansfer functions $f_{0}(z)=\hat{F}_{M}(z)=\hat{D}_{M}(z) / D_{M}(z)$ to prove the stability of the proposed $\mathrm{f}$ ilter. As $f_{0}(z)$ is a $\mathrm{n}$ a ll-pass $\mathrm{f}$ unction, whose 
denominator and numerator are expressed by $D_{M}(z)=A(z)$ and $\hat{D}_{M}(z)=z^{-M} D_{M}\left(z^{-1}\right)$ respectively, it can be af firmed that $\hat{H}(z)$ is stable iff $\hat{F}_{M}(z)$ is stable [47].

On o ne ha nd, b y u sing (26) in (23), a n e xpression f or $\hat{D}_{k-1}(z)$ as well as for $D_{k-1}(z)$ can be obtained. On the other hand, by studying both transfer functions for $k=M$, (27) yields, which shows up that $\sin \left(\theta_{M}\right)=f_{0}(0)$ is the first Schur parameter. F urthermore, a s traightforward recursive operation over (27) gives (28), s o that according to the S chur-Cohn stability te st, the IIR transfer function shown in (25), $\hat{H}(z)$, will be stable iff (29) holds.

$$
\begin{gathered}
f_{1}(z)=\frac{\hat{D}_{M-1}(z)}{D_{M-1}(z)}=z^{-1} \frac{\hat{D}_{M}(z) / D_{M}(z)^{-\sin \left(\theta_{M}\right)}}{1-\hat{D}_{M}(z) / D_{M}(z)^{\sin \left(\theta_{M}\right)}} \\
f_{k}(0)=\frac{\hat{D}_{M-k}(0)}{D_{M-k}(0)}=\sin \left(\theta_{M-k}\right), \quad k=0,1, \ldots, M-1 \\
\left|\sin \left(\theta_{M-k}\right)\right|<1
\end{gathered}
$$

It is important pointing out that (29) is always true except for the angles $\theta_{M-k}= \pm \pi / 2$. However, if this condition arises then the all-pass function becomes $f_{k}(z) \equiv 1$, as the zeros and the poles are located at the unit circle and consequently they cancel o ut. Mo reover, $t$ he $S$ chur $r$ ecursion makes $t$ hese reciprocal roots to cancel out at the output of the filter because of the same reason [32].

It $\mathrm{s}$ hould $\mathrm{b}$ e noted $\mathrm{t}$ hat $\mathrm{t}$ he obtained conclusion a bout stability is of a great interest when put together with the LMS algorithm. Since the r ecursive al gorithm is d esigned to f ind the Wiener solution by adapting the filter coefficients of the filter, the use of the S chur-lattice I IR s tructure $p$ roposed in Fig. 7(b), gives an inherently stable IIR filter regardless of the filter coefficients adaptation process.

\section{The Gradient Adaptive Lattice Algorithm (GAL)}

The af orementioned L MS method can be a pplied to the Schur-lattice IIR structure, so that the coefficients of the filter are recursively ad apted i $\mathrm{n}$ o rder $\mathrm{t} \mathrm{o} \mathrm{m}$ inimize $\mathrm{t}$ he q uadratic error function shown in (22). The recursive a lgorithm shown in (30) is o btained, w here $e(n)=y(n)-\hat{y}(n)$ is the error signal, $\mu$ is the learning $\mathrm{r}$ ate of $\mathrm{t}$ he ad aptive $\mathrm{f}$ ilter, an $\mathrm{d} t$ he filtered regressors could be obtained by applying (31).

$$
\left[\begin{array}{c}
b_{0}(n+1) \\
\vdots \\
b_{M}(n+1) \\
\theta_{1}(n+1) \\
\vdots \\
\theta_{M}(n+1)
\end{array}\right]=\left[\begin{array}{c}
b_{0}(n) \\
\vdots \\
b_{M}(n) \\
\theta_{1}(n) \\
\vdots \\
\theta_{M}(n+1)
\end{array}\right]+\mu e(n)\left[\begin{array}{c}
\nabla b_{0}(n) \\
\vdots \\
\nabla b_{M}(n) \\
\nabla \theta_{1}(n) \\
\vdots \\
\nabla \theta_{M}(n)
\end{array}\right]
$$

$$
\begin{array}{ll}
\nabla b_{k}(z)=x_{k+1}(z), & k=0,1, \ldots, M-1 \\
\nabla b_{M}(z)=w(z), & k=M \\
\nabla \theta_{k}(z)=\frac{\partial y(z)}{\partial \theta_{k}}, & k=0,1, \ldots, M
\end{array}
$$

\section{Adaptive Schur-Lattice IIR notch filter}

A Schur-lattice IIR notch filter is depicted in Fig. 8, which it is based on the Schur-lattice IIR filter realization depicted in Fig. 7. $T$ his $f$ ilter $r$ ealization performs the $t$ ransfer $f$ unction shown in (32), where $A P(z)$ is the a ll-pass transfer function defined in (33). The filter a llows the d esigner to a djust the notch frequency as well as the b andwidth by means of (34) and (35) respectively. The angles of the rotation matrix will be used to properly tune the notch filter.

$$
\begin{gathered}
\hat{G}_{n}(z)=\frac{1}{2}[1+A P(z)] \\
A P(z)=\frac{\sin \left(\theta_{2}\right)+\sin \left(\theta_{1}\right)\left(1+\sin \left(\theta_{2}\right)\right) z^{-1}+z^{-2}}{1+\sin \left(\theta_{1}\right)\left(1+\sin \left(\theta_{2}\right)\right) z^{-1}+\sin \left(\theta_{2}\right) z^{-2}} \\
\omega_{0}=\theta_{1}+\frac{\pi}{2}, \quad\left|\theta_{1}\right|<\frac{\pi}{2} \\
\sin \left(\theta_{2}\right)=\frac{1-\tan (B W / 2)}{1+\tan (B W / 2)}
\end{gathered}
$$

As shown in Fig. 6, the main problem of the fixed notches filters is its inability to adjust the center frequency if the utility grid $f$ requency varies. The ad aptive $\mathrm{S}$ chur-lattice I IR $\mathrm{n}$ otch filter can be u sed to ov ercome this dr awback, by using the GAL algorithm to automatically adapt the $\theta_{1}$ parameter.

In or der to find a solution to the G AL a lgorithm for the Schur-lattice IIR notch filter, the input signal of the filter, $u(n)$, is defined according to (36), where $\{\zeta(\cdot)\}$ is a n error signal statistically independent of $u(n), p_{1}$ is the a mplitude o f a sinusoidal s ignal of frequency $\omega_{1}$ and $T_{m}$ is the s ampling period of the discrete system.

$$
u(n)=p_{1} \sin \left(\omega_{1} T_{m} n\right)+\zeta(n)
$$

By defining the frequency response of the ideal notch filter as shown in (37), and taking into account that the output of the filter c ould b e written a s $y(z)=\hat{G}_{n}(z)[u(z)+\zeta(z)]$, the variance of the $\mathrm{f}$ ilter o utput is o btained b y means of (38), where $\sigma_{\zeta}^{2}$ is the variance of the input noise, and $\left\|\hat{G}_{n}(z)\right\|_{2}$ is the $L_{2}$ norm of $\hat{G}_{n}(z)$.

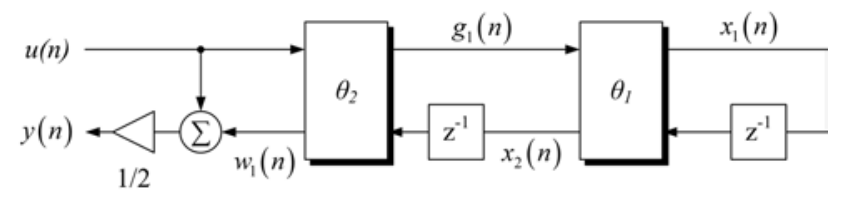

Fig. 8. A second order Schur-lattice IIR notch filter. 


$$
\begin{gathered}
\left|\hat{G}_{n}\left(e^{j \omega}\right)\right|= \begin{cases}0, & \omega=\left\{\omega_{0},-\omega_{0}\right\} \\
1, & \omega \neq\left\{\omega_{0},-\omega_{0}\right\}\end{cases} \\
E\left[y^{2}(n)\right]=p_{1}^{2}\left|\hat{G}_{n}\left(e^{j \omega_{1}}\right)\right|^{2}+\sigma_{\zeta}^{2}\left\|\hat{G}_{n}(z)\right\|_{2}^{2}
\end{gathered}
$$

By substituting (37) in (38), and assuming that the cen ter frequency o $\mathrm{ft}$ he Schur-lattice I IR $\mathrm{n}$ otch filter can vary according to the GAL algorithm that will be proposed shortly, (39) yields, from which it is p ossible to a ffirm that the function $E\left[y^{2}(n)\right]$ has a minimum when $\mathrm{t}$ he $\mathrm{c}$ ondition $\omega_{0}=\omega_{1}$ is satisfied.

$$
E\left[y^{2}(n)\right]= \begin{cases}\sigma_{\zeta}^{2}\left\|\hat{G}_{n}(z)\right\|_{2}^{2}, & \omega_{0}=\omega_{1} \\ p_{1}^{2}+\sigma_{\zeta}^{2}\left\|\hat{G}_{n}(z)\right\|_{2}^{2}, & \omega_{0} \neq \omega_{1}\end{cases}
$$

It can be proved that $\left\|\hat{G}_{n}(z)\right\|_{2}^{2}=0.5\left(1+\sin \left(\theta_{2}\right)\right)$, so that it does $\mathrm{n}$ ot $\mathrm{v}$ ary with $\mathrm{t}$ he parameter $\theta_{1}$. $\mathrm{T}$ herefore, an $\mathrm{d}$ considering (39), the cost function chosen to be minimized by the GAL algorithm is shown by (40).

$$
J=\frac{\partial E\left[y^{2}(n)\right]}{\partial \theta_{1}}
$$

Moreover, b y car efully ex amining (38), it c ould b e affirmed that minimizing $E\left[y^{2}(n)\right]$ respect $\mathrm{t} \quad \mathrm{o} \theta_{1}$ is equivalent to find the solution for $\left|\hat{G}_{n}\left(e^{j \omega_{1}}\right)\right|=0$. Taking into account the ideal frequency response of the notch filter, this is equivalent to make $\omega_{0}=\omega_{1}$, thus yielding $\theta_{1}=\omega_{1}+\frac{\pi}{2}$. This solution implies that the GAL Schur-lattice IIR filter does not need a reference to adaptively tune its center frequency. Hence, it is not necessary to feedback the estimated frequency.

In or der to a pply the G AL a lgorithm to the S chur-lattice IIR notch filter depicted in Fig. 8, the filtered regresor $\nabla \theta_{1}(z)$ has $\mathrm{t}$ o b e co mputed. By u sing (32), (41) holds, w here $T=0.5\left(\cos \left(\theta_{1}\right) \cos ^{2}\left(\theta_{2}\right)\right), \quad c_{1}=\sin \left(\theta_{1}\right)\left(1+\sin \left(\theta_{2}\right)\right) \quad$ and $c_{2}=1+\sin \left(\theta_{2}\right)$.

$$
\nabla \theta_{1}(z)=\frac{\partial y(z)}{\partial \theta_{1}}=T z^{-1} \frac{1-z^{-2}}{\left(1+c_{1} z^{-1}+c_{2} z^{-2}\right)^{2}} u(z)
$$

The schematic of the adaptive Schur-lattice IIR notch filter is depicted in Fig. 9, which could be implemented by means of the s implified G AL a lgorithm s hown i n Table IV [32]. A pseudo-code can be found in an Appendix at the end of this paper which clearly states the correct programing sequence.

\section{E. The Adaptive Lattice SRF-PLL}

The A daptive L attice S RF-PLL (A LSRF-PLL) i s j ust a modified phase estimator derived from that depicted in Fig. 4,

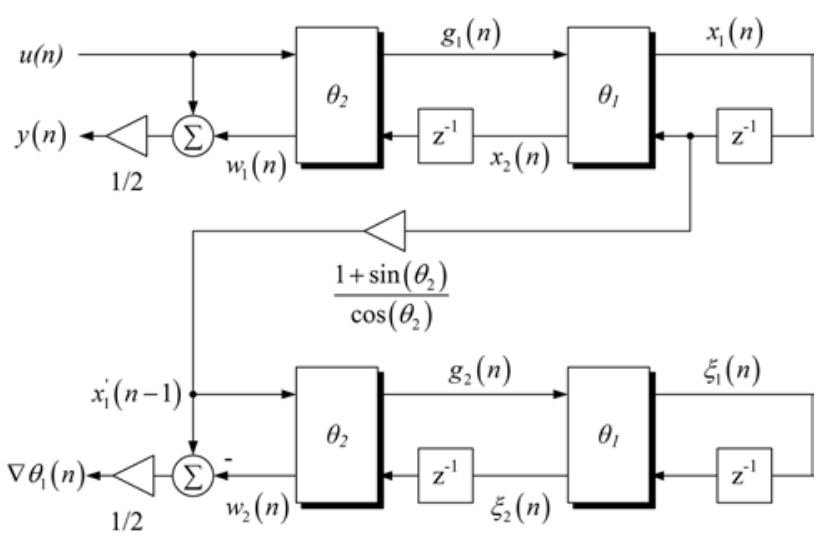

Fig. 9. A second order GAL Schur-lattice IIR notch filter.

TABLE IV

SiMPLIFIEd GAL ALGORITHM APPLIED TO THE SCHUR-LATTICE IIR NOTCH FILTER

Filter Parameters Computing

$$
\begin{gathered}
{\left[\begin{array}{l}
g_{1}(n) \\
w_{1}(n)
\end{array}\right]=\left[\begin{array}{cc}
\cos \left(\theta_{2}\right) & -\sin \left(\theta_{2}\right) \\
\sin \left(\theta_{2}\right) & \cos \left(\theta_{2}\right)
\end{array}\right]\left[\begin{array}{c}
u(n) \\
x_{2}(n-1)
\end{array}\right]} \\
{\left[\begin{array}{l}
x_{1}(n) \\
x_{2}(n)
\end{array}\right]=\left[\begin{array}{cc}
\cos \left(\theta_{1}(n)\right) & -\sin \left(\theta_{1}(n)\right) \\
\sin \left(\theta_{1}(n)\right) & \cos \left(\theta_{1}(n)\right)
\end{array}\right]\left[\begin{array}{c}
g_{1}(n) \\
x_{1}(n-1)
\end{array}\right]} \\
y(n)=\frac{1}{2}\left[u(n)+w_{1}(n)\right]
\end{gathered}
$$

Filter Parameters Adaptation

$$
\theta_{1}(n+1)=\theta_{1}(n)-\mu y(n) x_{1}(n-1)
$$

where $t$ he $f$ ixed notch filters, $G_{1}(z), \ldots, G_{n}(z)$ have b een replaced by the GAL Schur-lattice IIR notch filter depicted in

Fig. 9, cal led $\hat{G}_{2}(z), \hat{G}_{6}(z) \hat{G}_{12}(z)$. Fig. 10(a) s hows t he simplified block diagram of the ALSRF-PLL, which includes the adaptive filtering stage. The small signal model is depicted in Fig. 10(b). Each of the used adaptive filters adapts its notch frequency $t$ o each o $f$ the $d$ isturbances considered. As previously stated, this adaptation does not need any reference signal, as the GAL a lgorithm a utomatically finds out each of the $u$ ndesired $h$ armonics. It is worth pointing o ut th at, s ince the filters are cascade connection, once a harmonic has been removed $b$ y the $p$ revious s tage, ne $x t$ stage $w$ ill $n$ ot $f$ ind it again. I $\mathrm{n} t$ his $\mathrm{r}$ egard, th e tr ansitory $\mathrm{r}$ ipple in th e e stimated frequency does not affect the adaptation process, since it is no needed at all.

In o rder to in itialize the ALSRF-PLL, the va lues of the parameters s hown in Table $\mathrm{V}$ are u sed. $\theta_{1}$ h(initial) is the initial value of the parameter $\theta_{1}$ of the filter designed to reject the $h^{\text {th }}$ harmonic (i.e. $2^{\text {nd }}, 6^{\text {th }}$ or $12^{\text {th }}$ ). $\mu \_h$ is the learning rate of the adaptive notch filter with in itial notch frequency equal to the $h^{\text {th }}$ harmonic. Finally, $\theta_{2}$ is related with the bandwidth of the filter according to (35). It is worth pointing out that a low $\mathrm{Q}$ filter is usually designed when us ing $\mathrm{f}$ ixed frequency notches, $b$ ecause this as sure $a b$ etter $f$ iltering $p$ erformance even if the frequency varies. As the adaptive filter 


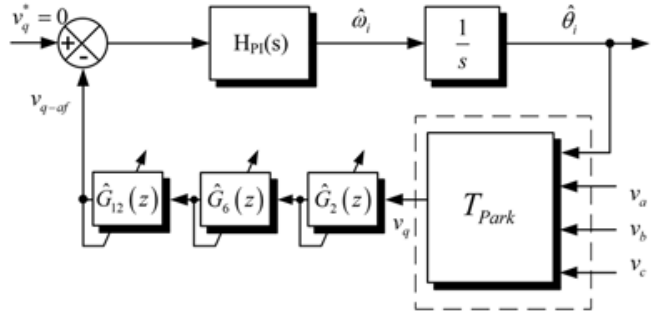

(a)

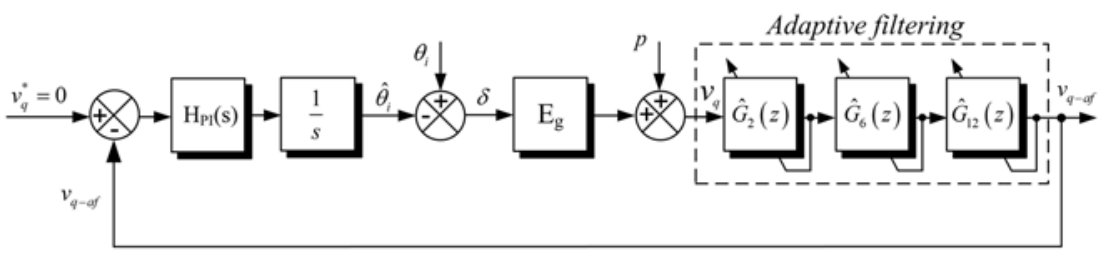

(b)

Fig. 10. (a) Basic block diagram and (b) small signal block diagram of an ALSRF-PLL.

TABLE V

PARAMETERS OF THE ALSRF-PLL

\begin{tabular}{cc}
\hline \hline Parameter & Value \\
\hline$\theta_{1 \_2}$ (initial) & -1.531526418 \\
$\omega_{0 \_}$ & $2 \pi 100 \mathrm{rad} / \mathrm{s}$ \\
$\theta_{2 \_} 2$ & 1.445132620 \\
BW_2 & $20 \mathrm{~Hz}$ \\
$\mu \_2$ & 0.0001 \\
$\theta_{1 \_6}$ (initial) & -1.452986602 \\
$\omega_{0 \_} 6$ & $2 \pi 300 \mathrm{rad} / \mathrm{s}$ \\
$\theta_{2 \_} 6$ & 1.445132620 \\
BW_6 & $20 \mathrm{~Hz}$ \\
$\mu \_6$ & 0.0001 \\
$\theta_{1 \_12(i n i t i a l)}$ & -1.335176877 \\
$\omega_{0 \_12}$ & $2 \pi 600 \mathrm{rad} / \mathrm{s}$ \\
$\theta_{2 \_12}$ & 1.445132620 \\
BW_12 & $20 \mathrm{~Hz}$ \\
$\mu \_12$ & 0.01
\end{tabular}

automatically ad apts i ts ce nter f requency, a low Q is not required. I $\mathrm{nt}$ his $\mathrm{r}$ egard, at rade-off $\mathrm{b}$ etween $\mathrm{s}$ peed convergence during transitory times and phase margin of the ALSRF-PLL has to be found. U sually, $\theta_{2}$ is c hosen so that enough phase margin is obtained at the crossover frequency, when the frequency of the voltage gr id is o $n$ the minimum considered, while maintaining the equivalent S RF-PLL speed of convergence when a variation on the frequency appears.

\section{EXPERIMENTAL RESULTS}

The A LSRF-PLL $\mathrm{h}$ as $\mathrm{b}$ een implemented i nto $\mathrm{t}$ he $\mathrm{f}$ ixed point D SP T I TMS320F2812. The t hree-phase u tility grid voltage has been emulated by means of the $12 \mathrm{kVA} A C$ power source $\mathrm{P}$ acific $\mathrm{P}$ ower 3 60-AMX. The A C p ower s ource $\mathrm{h}$ as been $\mathrm{p}$ rogrammed $\mathrm{s}$ ot hat an $\mathrm{u}$ nbalance a d istorted $\mathrm{g}$ rid suddenly ap pears. At a given moment, the frequency of the unbalanced a nd di storted voltage grid described in (7) and Table II abruptly $\mathrm{v}$ aries. T herefore, an i nherit $\mathrm{p}$ hase-angle jump is a lso taken into a ccount. The ope $\mathrm{n}$ loop $\mathrm{g}$ ain of the ALSRF-PLL, $\quad \hat{T}_{P L L}(z)=-E_{g} H_{P I}(z) \hat{G}_{2}(z) \hat{G}_{6} \hat{G}_{12}(z) \operatorname{Int}(z)$, has $\mathrm{b}$ een measured by means o $\mathrm{ft}$ he frequency $\mathrm{r}$ esponse analyzer ( FRA) N F F RA5097 [48]. The $r$ eal t ime d ata has been $r$ ead $f$ rom $t$ he DSP $b$ y using $t$ he RTDX co re [49]; MATLAB has been used to process and to plot the collected data. The obtained Bode plots are depicted in Fig. 11, for the nominal, the $\mathrm{m}$ inimum and the $\mathrm{m}$ aximum $\mathrm{f}$ requencies $\mathrm{u}$ nder study, i.e. $50 \mathrm{~Hz}, 45 \mathrm{~Hz}$, and $55 \mathrm{~Hz}$, r espectively. The ch osen frequencies are according $\mathrm{t}$ ot he nominal, minimum a nd maximum frequency included in norms as the UNE-EN 50160 [50].

On the one hand, the correct behavior of the adaptive filters is cl early ap preciable in Fig. 11, a s the no tch frequency of each of the filters varies according to the frequency variation of the grid voltage. On the other hand, it should be noted that the minimum phase margin is $P M=73.5^{\circ}$ at $f_{c}=44 \mathrm{~Hz}$, when the frequency of the grid voltage at the PCC is $f_{i}=45 \mathrm{~Hz}$, whereas the $\mathrm{m}$ aximum phase $\mathrm{m}$ argin is $P M=77.2^{\circ}$ at $f_{c}=44 \mathrm{~Hz}$ when $f_{i}=55 \mathrm{~Hz}$. The no minal phase margin is $P M=75.3^{\circ}$ at $f_{c}=44 \mathrm{~Hz}$ when $f_{i}=50 \mathrm{~Hz}$. Those phase margins are high enough to assure that the ALSRF-PLL is stable when the grid voltage frequency at the $\mathrm{PCC}$ varies from $f_{i}=45 \mathrm{~Hz}$ to $f_{i}=55 \mathrm{~Hz}$.

In Fig. 12 it is depicted the unbalance and distorted threephase utility grid voltages used to test the conventional SRFPLL, the fixed notch filtered SRF-PLL and the ALSRF-PLL. First of all, the conventional SRF-PLL has been programmed into $t$ he D SP, s o that the e stimated $\mathrm{p}$ hase $\mathrm{c}$ an be o btained

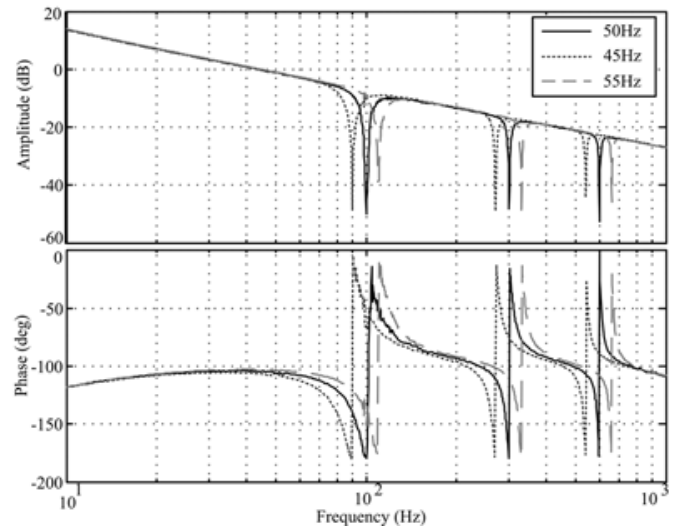

Fig. 11. Experimental open loop gains, $T_{P L L}^{\prime}$, of the ALSRF-PLL for the maximum, the minimum, and the nominal considered electric grid frequencies.

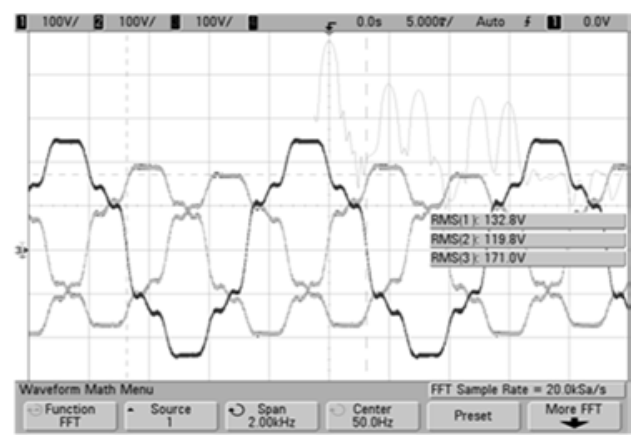

Fig. 12. Unbalanced and distorted three-phase utility grid AC power source voltages. 
when $\mathrm{t}$ he utility gr id voltage $\mathrm{i}$ she avily distorted a nd unbalance. Fig. 13(a) shows the sensed $v_{a b}(t)$ voltage (i.e. the phase $t \mathrm{o} p$ hase voltage), where $\mathrm{t}$ he $\mathrm{h}$ armonic $\mathrm{d}$ istortion is clearly ap preciable. In Fig. 13(b) it is s hown the e stimated phase, $\hat{\theta}_{i}$, where it is possible to notice that a ripple exists due to the $2^{\text {nd }}$, the $6^{\text {th }}$ and the $12^{\text {th }}$ harmonics. Furthermore, in the $v_{q}(t)$ signal depicted in Fig. 13(c), the ripple is much more appreciable. A sinusoidal signal, $\sin \left(\hat{\theta}_{i}\right)$, has been generated by means of the estimated phase shown in Fig. 13(b), and the FFT of this signal has been computed, thus obtaining the result shown in Fig. 14. This result clearly shows the $1^{\text {st }}$ harmonic (i.e. $50 \mathrm{~Hz}$ ), the $3^{\text {rd }}$ harmonic (i.e. $150 \mathrm{~Hz}$ ), the $5^{\text {th }}$ harmonic (i.e. $250 \mathrm{~Hz}$ ), the $7^{\text {th }}$ harmonic (i.e. $350 \mathrm{~Hz}$ ), the $11^{\text {th }}$ harmonic (i.e. $550 \mathrm{~Hz}$ ) and the $13^{\text {th }}$ harmonic (i.e. $650 \mathrm{~Hz}$ ). It should be noted that the $3^{\text {rd }}$ harmonic is due to the effect of the reference frame translation to the unbalance harmonic in the $\mathrm{S} R F$, so that $\mathrm{t}$ his harmonic ( i.e $2^{\text {nd }}$ harmonic), $\mathrm{b}$ ehaves 1 ike $\mathrm{t}$ he $3^{\text {rd }}$ harmonic in the NRF.

In o rder to remove these unwanted $\mathrm{h}$ armonics, $\mathrm{w}$ hich degrade the current THD of the converter current [9], the fixed notch $f$ ilters pr eviously de scribed $h$ ave been i ncluded. The filtered SRF-PLL behavior has been tested both at the nominal grid frequency a nd a $\mathrm{ta}$ gr id frequency different from $\mathrm{t}$ he nominal one. In order to set up the experiment, the $\mathrm{AC}$ power
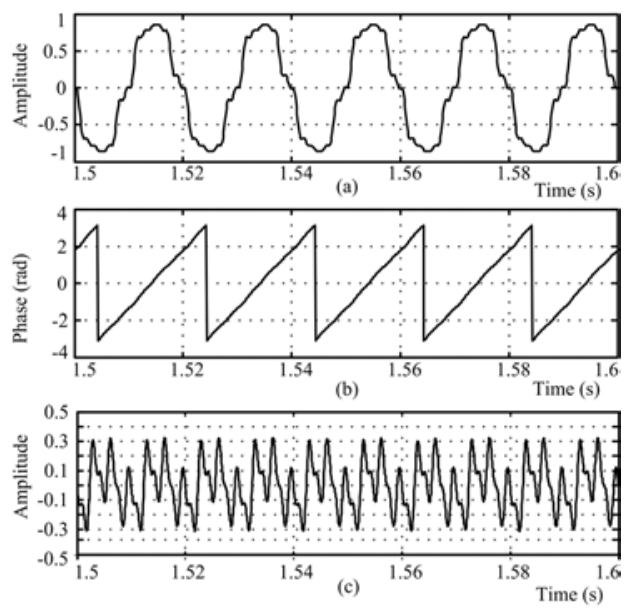

Fig. 13. Experimental (a) sensed line voltage, $V_{a b}$, (b) estimated phase, $\hat{\theta}_{i}$ and (c) $v_{q}$ signal for the unbalanced and distorted electric grid shown in Fig. 12.

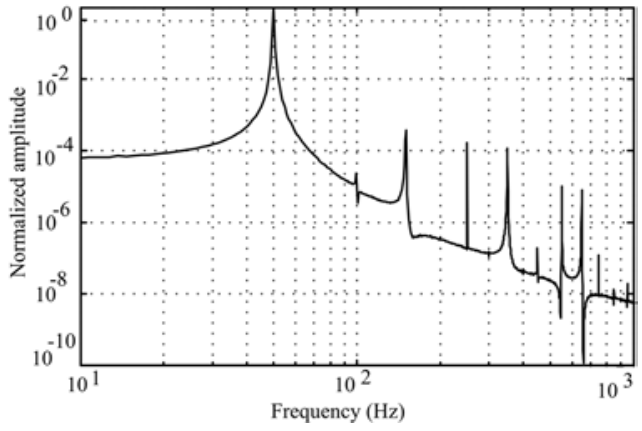

Fig. 14. FFT of a sinusoidal reference, $\sin \left(\hat{\theta}_{i}\right)$, obtained by means of the estimated phase, $\hat{\theta}_{i}$, of a conventional SRF-PLL. source ha $\mathrm{s}$ b een p rogrammed s o that the i nitial c ondition of the emulated grid voltage has neither unbalance nor harmonic distortion. At a given instant of time, the grid voltage is varied so that it contains the aforementioned unbalance and harmonic distortion, whereas maintaining the $\mathrm{s}$ ame frequency (i.e. the nominal frequency of $50 \mathrm{~Hz}$ ). F inally, $t$ he $f$ requency of the distorted an $\mathrm{d} u$ nbalance $\mathrm{t}$ hree-phase grid vo ltage i s va ried from the nominal one (i.e. $50 \mathrm{~Hz}$ ), to the maximum frequency considered (i.e. $55 \mathrm{~Hz}$.), and then the three-phase grid voltage is returned to the initial condition (i.e. neither unbalance nor distortion with a frequency of $50 \mathrm{~Hz}$ ).

Fig. 15 shows the $v_{q}(t)$ and the filtered $v_{q f}(t)$ signals of the notch filtered S RF-PLL wh en: 1 . (from $t \approx 0$ s until $t \approx 0.5 \mathrm{~s}$ ) Neither unbalance nor di stortion exists, a nd the frequency is $50 \mathrm{~Hz} ; 2$. (from $t \approx 0.5 \mathrm{~s}$ until $t \approx 1.5 \mathrm{~s}$ ) The unb alance a nd the distortion are abruptly i ntroduced, maintaining the no minal frequency 3. (from $t \approx 1.5$ until $t \approx 2.5 \mathrm{~s}$ ) The frequency of the distorted and unbalanced set of voltages is varied from $50 \mathrm{~Hz}$ to $55 \mathrm{~Hz}$. It is worth mentioning that the $\mathrm{t}=0 \mathrm{~s}$ has been chosen to be the moment the RTDX algorithm starts sending data to the PC, and not the moment the notch filtered SRF-PLL starts working. In fact, the notch filtered SRF-PLL is in its steady state when the change of the voltage frequency takes place, so that the start-up sequence of the synchronization a lgorithm is not shown. Anyway, as the initial conditions of the SRF-PLL is chosen to be $\hat{\omega}_{i}=2 \pi \hat{f}_{i} \mathrm{rad} / \mathrm{s}$, where $\hat{f}_{i}$ is the expected grid frequency, the start-up transient is not important compared to the transient due to the variation of the voltage grid frequency.

As the $\mathrm{n}$ otch $\mathrm{f}$ ilters ar e $\mathrm{d}$ esigned by $\mathrm{c}$ onsidering a $\mathrm{f}$ ixed nominal frequency of $50 \mathrm{~Hz}$, they perform as ex pected from $t \approx 0$ s until $t \approx 0.5 \mathrm{~s}$, since the ripple in $v_{q f}(t)$ is strongly filtered out. However, when the no minal frequency varies from $50 \mathrm{~Hz}$ to $55 \mathrm{~Hz}$, the filters are not able to reject the disturbances, so that the $v_{q f}(t)$ signal does contain almost all the ripple found in the $v_{q}(t)$ signal. This is conveniently shown in Fig. 16(a) and Fig. 16(b), where the F FT of the normalized $v_{q}(t)$ and $v_{q f}(t)$ signals (i.e. respect to the $3^{\text {rd }}$ harmonic amplitude), has been computed when the grid frequency is (a) $50 \mathrm{~Hz}$, and (b) $55 \mathrm{~Hz}$.

By e xamining $b$ oth $p$ lots, it i s possible to a ffirm that the $2^{\text {nd }}, 6^{\text {th }}$ and $12^{\text {th }}$ harmonics a re strongly attenuated when the

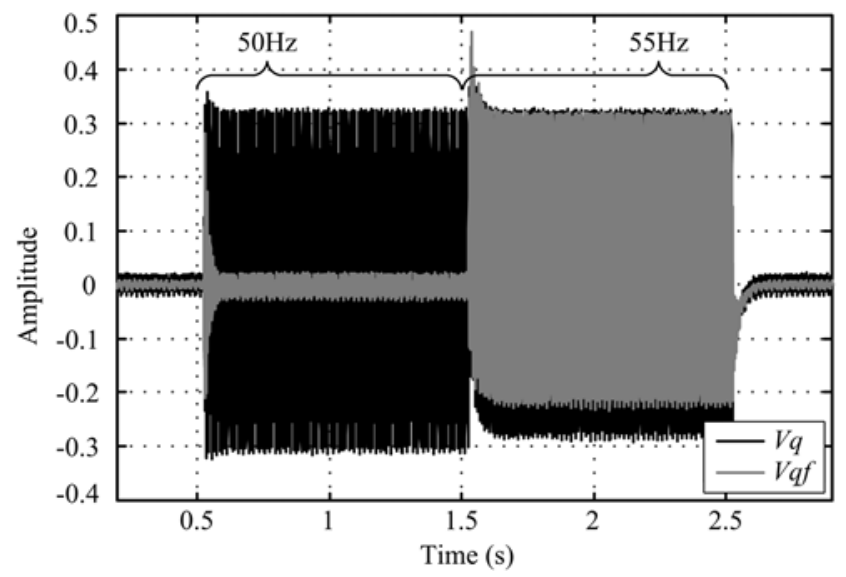

Fig. 15. $v_{q}$ (black) and $v_{q f}$ (grey) signals of a selective filtered SRF-PLL, for the $\mathrm{u}$ nbalanced a nd distorted e lectric $\mathrm{g}$ rid s hown in $\mathrm{F}$ ig. 12 , w hen $\mathrm{t}$ he frequency is tuned at $50 \mathrm{~Hz}$ and at $55 \mathrm{~Hz}$. 


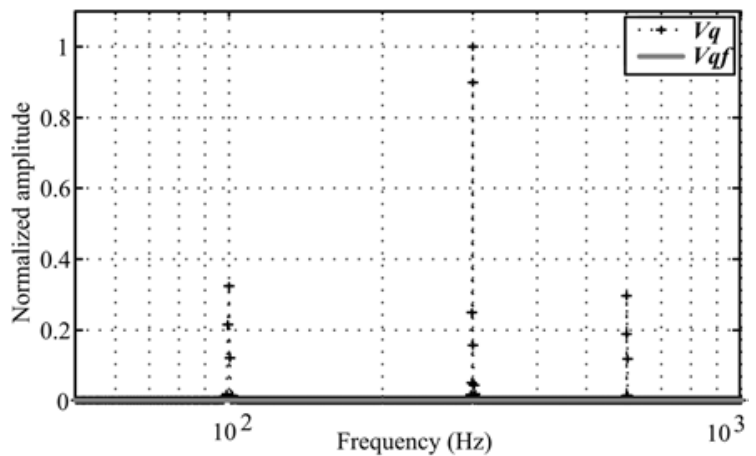

(a)

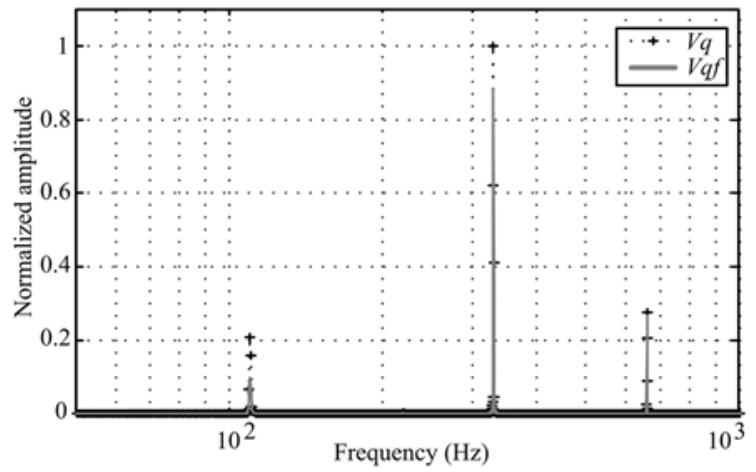

(b)

Fig. 16. Normalized $v_{q}$ (black-dotted) and $v_{q f}$ (grey-solid) signals of a selective filtered SRF-PLL, for the unbalanced and distorted electric grid shown in Fig. 12 when the frequency is tuned at (a) $50 \mathrm{~Hz}$ and (b) $55 \mathrm{~Hz}$.

frequency is fixed and equal to the nominal o ne (i.e. $50 \mathrm{~Hz}$ ). However, those harmonics are still at the output of the fixed notches when $\mathrm{t}$ he f requency o $\mathrm{ft}$ he fundamental harmonic varies. This has been numerically evaluated by means of the attenuation value shown in Table VI. As previously stated, the ripple on the $v_{q f}(t)$ signal, (and thus the ripple on the estimated phase), can b ef ound at the s inusoidal $r$ eference, $I^{*}=I_{M} \sin \left(\hat{\theta}_{i}\right)$, used to control the current loop of the power converter. Fig. 17 shows the FFT of the $\sin \left(\hat{\theta}_{i}\right)$ in a nonadaptive selective filtered SRF-PLL, showing that the performance of the power converter is sensitive to a $\mathrm{v}$ ariation on the grid frequency.

The $\mathrm{s}$ ame e xperiment has $\mathrm{b}$ een $\mathrm{c}$ arried o ut b y using the proposed ALSRF-PLL. Fig. 18 shows the $v_{q}(t)$ and the $v_{q-a f}(t)$ signals $w$ hen a $v$ ariation of the aforementioned grid voltage has $\mathrm{b}$ een $\mathrm{p}$ rogrammed in the $\mathrm{A} \mathrm{C} \mathrm{p}$ ower s ource. It is $\mathrm{w}$ orth pointing out that $\mathrm{t}=0 \mathrm{~s}$ is chosen to be the moment the RTDX algorithm s tarts working. Furthermore, the initial coefficients of the adaptive filters have been chosen so that the filters are tuned at the ex pected harmonic frequency (i.e. second, sixth and twelfth harmonics).

TABLE VI

Disturbances ATtenuATION By MEANS OF THE IIR FIXED NotChES

\begin{tabular}{c|cc}
\hline \hline \multirow{2}{*}{ Harmonic number } & \multicolumn{2}{|c}{ Attenuation $(\mathrm{dB})$} \\
\cline { 2 - 3 } & $50 \mathrm{~Hz}$ & $55 \mathrm{~Hz}$ \\
\hline 2 & -120.2 & -6.5 \\
6 & -114.1 & -1.1 \\
12 & -111.2 & -0.3
\end{tabular}

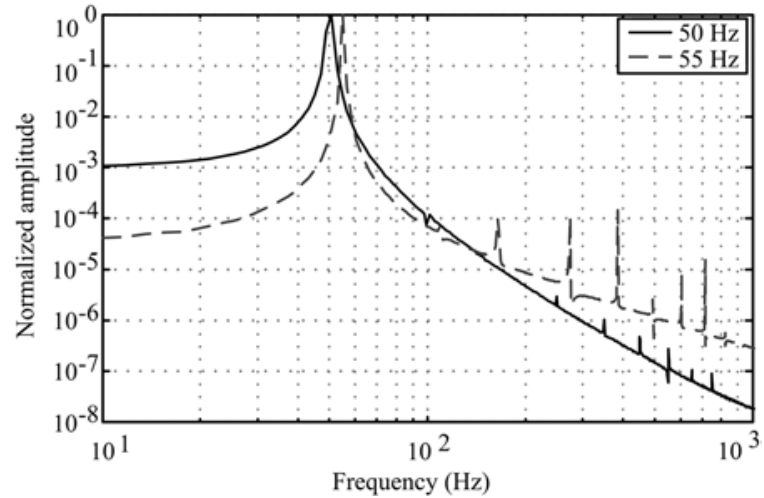

Fig. 17. FFT of a sinusoidal reference, $\sin \left(\hat{\theta}_{i}\right)$, obtained by means of the estimated phase, $\hat{\theta}_{i}$, of a selective filtered SRF-PLL, for an unbalanced and distorted electric grid which frequency is $50 \mathrm{~Hz}$ (black-solid) and $55 \mathrm{~Hz}$ (grey-dotted).

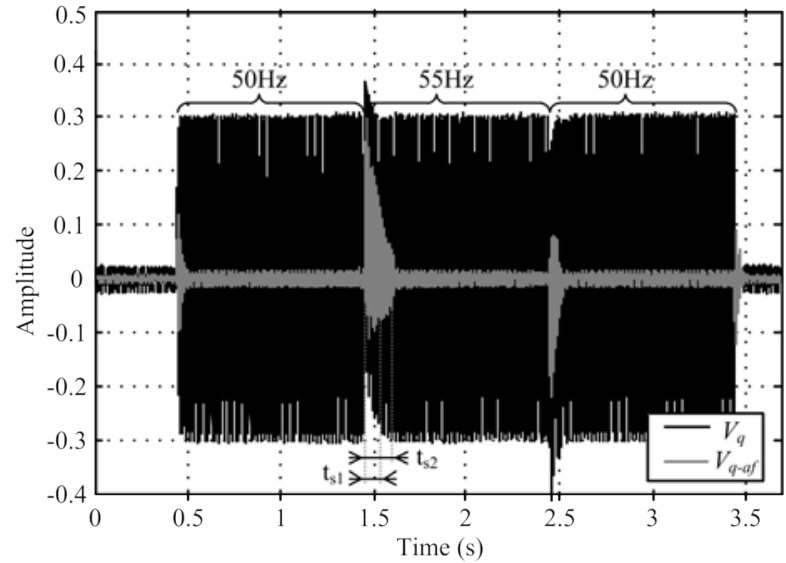

Fig. 18. $v_{q}$ (black) and $v_{q-a f}$ (grey) of a ALSRF-PLL, for the unbalanced and distorted electric grid shown in Fig. 12, when the frequency is tuned at $50 \mathrm{~Hz}$ and at $55 \mathrm{~Hz}$

The good performance o $\mathrm{f}$ th $\mathrm{e}$ a daptive $\mathrm{n}$ otch filter implemented by means of the Schur-lattice structure is clearly noticiable, for a ripple-free filtered signal $v_{q-a f}(t)$ is obtained regardless of the frequency of the utility grid. T he F FT has been a pplied to b oth signals, $v_{q}(t)$ and $v_{q-a f}(t)$, when the grid frequency is $50 \mathrm{~Hz}$ and $55 \mathrm{~Hz}$. The result is shown in Fig. 19(a) and in Fig. 19(b), respectively. It can b e observed that the adaptive notch filter strongly rejects the disturbances in both cases, as shown in Table VII. A sinusoidal reference has been generated b y means of $\mathrm{t}$ he $50 \mathrm{~Hz}$ an $\mathrm{d} t$ he $55 \mathrm{~Hz}$ ad aptively filtered estimated phase in the steady state. The FFT of these signals a re plotted in Fig. 20, from which it is p ossible to affirm that the harmonics due to the unbalance and the distortion are negligible

It is important pointing out that the convergence or learning rate $\mathrm{p}$ arameter, $\mu$, has $\mathrm{b}$ een ch osen $\mathrm{i} \mathrm{n}$ o rder $\mathrm{t} \mathrm{o}$ ach ieve a compromise between stability and convergence speed. On one hand, the value of $\mu$ has to a llow obtaining a stable a daptive filter ( i.e. a f ast filter, with a g reat $\mu$, c ould $\mathrm{r}$ esult i $\mathrm{n}$ an unstable filter). $\mathrm{O} n$th e o ther $h$ and, th is $\mathrm{p}$ arameter $\mathrm{h}$ as to $\mathrm{be}$ adjusted $\mathrm{s} o \mathrm{t}$ hat $\mathrm{t}$ he $\mathrm{t}$ ime the ALSRF-PLL $\mathrm{t}$ akes $\mathrm{t} \mathrm{o}$ a chieve convergence is similar to the time the conventional SRF-PLL needs to correctly estimate the phase of the first harmonic (i.e. 


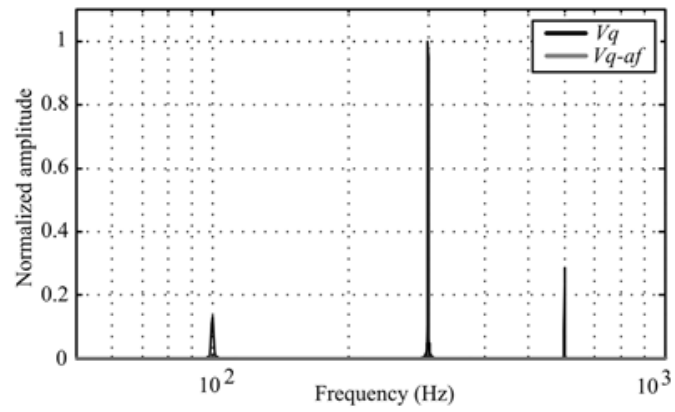

(a)

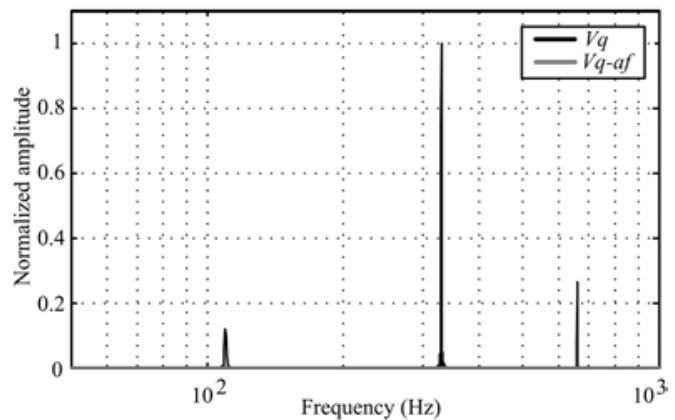

(b)

Fig. 19. Normalized $v_{q}$ (black-solid) and $v_{q-a f}$ (grey-solid) signals of an ALSRF-PLL, for the unbalanced and distorted electric grid shown in Fig. 12 when the frequency is tuned at (a) $50 \mathrm{~Hz}$ and (b) $55 \mathrm{~Hz}$.

TABLE VII

Disturbances ATtENUATION BY MEANS OF THE IIR ADAPTIVE NOTCHES

\begin{tabular}{c|cc}
\hline \multirow{2}{*}{ Harmonic number } & \multicolumn{2}{|c}{ Attenuation $(\mathrm{dB})$} \\
\cline { 2 - 3 } & $50 \mathrm{~Hz}$ & $55 \mathrm{~Hz}$ \\
\hline 2 & -90.3 & -94.5 \\
6 & -100.6 & -105.0 \\
12 & -121.4 & -150.7
\end{tabular}

the greater the $\mu$ parameter, the faster the adaptive filter). By achieving these goals, the a daptive IIR filter is s table and it does not make the response of the ALSRF-PLL significantly slower than the conventional S RF-PLL, as ca $\mathrm{n}$ be seen in Fig. 15 and Fig. 18, where $t_{\mathrm{s} 1} \approx 0.5 \mathrm{~s}$ is the settling time of the SRF-PLL a nd $t_{s 2} \approx 0.75 \mathrm{~s}$ is th e s ettling ti me o $\mathrm{ft}$ he ALSRF-PLL, bot $\mathrm{h}$ measured a $\mathrm{t} 5 \%$ of $\mathrm{t}$ he final va lue. Although the extra time $t_{\mathrm{s}} \approx 0.25 \mathrm{~s}$ appears due to the adaptive algorithm, it should be noted that the undesired harmonics of the $v_{q}$ component are highly attenuated during this transition time. Hence, they do not critically af fect the es timated phase during transitions.

The time consumption of each of the studied synchronization methods, along with the attenuation of the $2^{\text {nd }}$ harmonic in the $v_{q}$ variable, is shown in Table VIII. It should be $\mathrm{n}$ oted th at $\mathrm{t}$ his a ttenuation is not a pplicable to th $\mathrm{e}$ conventional SRF-PLL, so that it is not shown.

\section{CONCLUSIONS}

An SRF-PLL with adaptive disturbance rejection properties has been presented. The ALSRF-PLL is able to strongly reject the $d$ isturbances $d$ ue $t$ ot he gr id vo ltage unbalance a nd harmonic distortion regardless of variations of the grid voltage

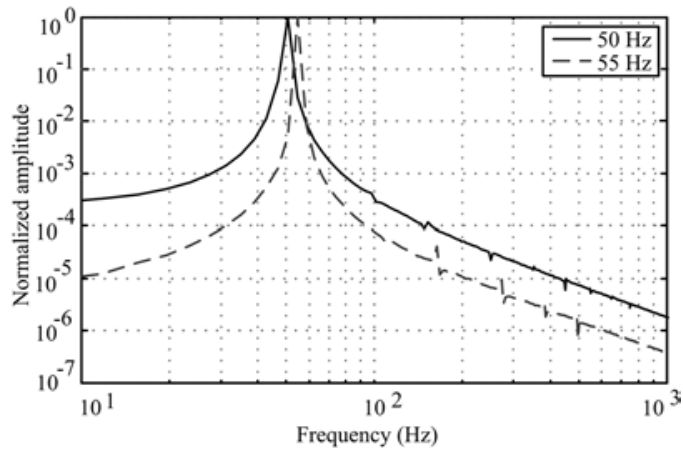

Fig. 20. FFT of a sinusoidal reference, $\sin \left(\hat{\theta}_{i}\right)$, obtained by means of the estimated phase, $\hat{\theta}_{i}$, of a ALSRF-PLL, for an unbalanced and distorted electric grid which frequency is $50 \mathrm{~Hz}$ (black-solid) and $55 \mathrm{~Hz}$ (grey-dotted).

TABLE VIII TIME CONSUPTION VS. $2^{\text {ND }}$ HARMONIC ATTENUATION

\begin{tabular}{c|c|cc}
\hline \hline & \multirow{2}{*}{ Synchronization method } & \multicolumn{2}{|c}{$\begin{array}{c}2^{\text {nd }} \text { harmonic } \\
\text { Attenuation }(\mathrm{dB})\end{array}$} \\
\cline { 3 - 4 } & & $50 \mathrm{~Hz}$ & $55 \mathrm{~Hz}$ \\
\hline SRF-PLL & 1.7 & - & - \\
SRF-PLL + Fixed Notch & 2.7 & -120.2 & -6.5 \\
ALSRF-PLL & 7.9 & -90.3 & -94.5
\end{tabular}

frequency. The presented synchronization method is based on the a daptive filtering of the grid vo ltage $q$ term of the S RF projection. A s et of I IR notch filters implemented b y the Schur-lattice s tructure an $d t$ he G AL $r$ ecursive method $h$ ave been used. This structure is inherently stable regardless of the coefficient adaptation process and offers some of the desired properties to be programed into a fixed point DSP. Furthermore, e xisting S RF-PLL c ould be e asily updated s o that they become adaptive. It offers a good chance to add new features to existing power converters, thus improving its original performance.

The ex perimental results ha ve s hown that the s tability of the whole ALSRF-PLL system (i.e. SRF-PLL + Schur-lattice + GAL structure) is as sured even in the worst case (i.e. when the vo ltage gr id $f$ requency $i \mathrm{~s} t$ he minimum o ne $u$ nder consideration). Furthermore, $t$ he ALSRF-PLL i s a ble to provide large fixed d isturbance a ttenuation, regardless of abrupt variations of the grid voltage frequency and of the grid voltage $u$ nbalance. $T$ herefore, $t$ he harmonics o ther $t$ han $t$ he fundamental of a s inusoidal $r$ eference o btained by means of the estimated phase can be considered negligible.

The $\mathrm{c}$ omputational $\mathrm{b}$ urden o $\mathrm{ft}$ he ALSRF-PLL is $\mathrm{q}$ uite larger than the SRF-PLL. Although the fixed notch SRF-PLL could be a $t$ rade-off s olution, it is $\mathrm{c}$ learly s hown $\mathrm{t}$ hat $\mathrm{t}$ his synchronization method i $\mathrm{s}$ ot well suited for a pplications where a va riation in the frequency of the voltage grid may occur.

In future works, a $\mathrm{n}$ i mproved $\mathrm{c}$ omputational bu rden i s expected $t \mathrm{o} b$ e o btained. F urthermore, $t$ he $\mathrm{S}$ chur-latice I IR filter could be also exploited so that it becomes the core of the three-phase power converter control scheme. 


\section{APPENDIX}

In o rder $\mathrm{t}$ o $\mathrm{c}$ larify $\mathrm{t}$ he a lgorithm $\mathrm{s}$ hown i $\mathrm{n}$ Table IV, a pseudo code of the filtering process is shown in Fig. 21. The first 1 ines define the co nstant $p$ arameters (i.e. $\mu \_n$ and $\theta_{2} n$, where $n$ is the harmonic number to be filtered out). The global variables are defined next, where the initial values of the $\theta_{1-} n$ variables are chosen so that the IIR adaptive filters are tuned at the expected harmonics frequencies, while the state variables $x 1 k 1 \_n$ could be initialized to zero. The main algorithm code consists of the code for the three filters, where the input of the first one is the $v_{q}$ component, while its output feds the second one (i.e. they are cascade connected). Eventually, the output of the third filter is the filtered $v_{q}$ component (i.e. $v_{q_{\_} a f}$ ).

\section{REFERENCES}

[1] J. M. Guerrero, F. Blaabjerg, T. Zhelev, K. Hemmes, E. Monmasson, S. Jemei, M. P. Comech, R. Granadino, and J. I. Frau, "Distributed Generation: Toward a New Energy Paradigm," Industrial Electronics Magazine, IEEE, vol. 4, no. 1, Mar.2010, pp. 52-64.

[2] H. Rudnick and L. A. Barroso, "On the Winds of Change Impact of Renewables on Electricity Markets [Guest Editorial]," Power and Energy Magazine, IEEE, vol. 8, no. 5, Sept.2010, pp. 18-21.

[3] L. Dickerman and J. Harrison, "A New Car, a New Grid," Power and Energy Magazine, IEEE, vol. 8, no. 2, Mar.2010, pp. 55-61.

[4] K. J. Dyke, N. Schofield, and M. Barnes, "The Impact of Transport Electrification on Electrical Networks," Industrial Electronics, IEEE Transactions on, vol. 57, no. 12, Dec.2010, pp. 3917-3926.

[5] F. Blaabjerg, R. Teodorescu, M. Liserre, and A. V. Timbus, "Overview of Control and Grid Synchronization for Distributed Power Generation Systems," IEEE Transaction on Industrial Electronics, vol. 53, no. 5, 2006, pp. 1398-1409.

[6] I. J. Balaguer, L. Qin, Y. Shuitao, U. Supatti, and Z. P. Fang, "Control for Grid-Connected and Intentional Islanding Operations of Distributed Power Generation," Industrial Electronics, IEEE Transactions on, vol. 58, no. 1, Jan.2011, pp. 147-157.

[7] O. Carranza, E. Figueres, G. Garcer $\beta$, and L. G. Gonzalez, "Comparative study of speed estimators with highly noisy measurement signals for Wind Energy Generation Systems," Applied Energy, vol. 88, no. 3, Mar.2011, pp. 805-813.

[8] E. Figueres, G. Garcera, J. Sandia, F. Gonzalez-Espin, and J. C. Rubio, "Sensitivity Study of the Dynamics of Three-Phase Photovoltaic Inverters With an LCL Grid Filter," Industrial Electronics, IEEE Transactions on, vol. 56, no. 3, 2009, pp. 706-717.

[9] M.P.Kazmierkowski, R.Krishnan, and F.Blaabjerg, Control in Power Electronics. Selected Problems., 1st. ed. Academic Press, San Diego, 2002.

[10] S. Hiti, D. Borojevic, R. Ambatipudi, R. Zhang, and J. Yimin, "Average current control of three-phase PWM boost rectifier," 26th Annual Power Electronics Specialists Conference. PESC '95 1995, pp. 131-137.

[11] C. Lascu, L. Asiminoaei, I. Boldea, and F. Blaabjerg, "Frequency Response Analysis of Current Controllers for Selective Harmonic Compensation in Active Power Filters," Industrial Electronics, IEEE Transactions on, vol. 56, no. 2, 2009, pp. 337-347.

[12] D. Velasco, C. Trujillo, G. Garcera, and E. Figueres, "An active Antiislanding method based on phase-PLL perturbation," Power Electronics, IEEE Transactions on, vol. PP, no. 99, 2010, p. 1.

[13] H. Guan-Chyun and J. C. Hung, "Phase-locked loop techniques. A survey," Industrial Electronics, IEEE Transactions on, vol. 43, no. 6, 1996, pp. 609-615.

[14] R. M. Santos Filho, P. F. Seixas, P. C. Cortizo, L. A. B. Torres, and A. F. Souza, "Comparison of Three Single-Phase PLL Algorithms for UPS Applications," Industrial Electronics, IEEE Transactions on, vol. 55, no. 8, Aug.2008, pp. 2923-2932.

[15] A. Timbus, M. Liserre, R. Teodorescu, P. Rodriguez, and F. Blaabjerg, "Evaluation of Current Controllers for Distributed Power Generation Systems," Power Electronics, IEEE Transactions on, vol. 24, no. 3, 2009, pp. 654-664.

[16] C. Se-Kyo, "A phase tracking system for three phase utility interface inverters," Power Electronics, IEEE Transactions on, vol. 15, no. 3, 2000, pp. 431-438.

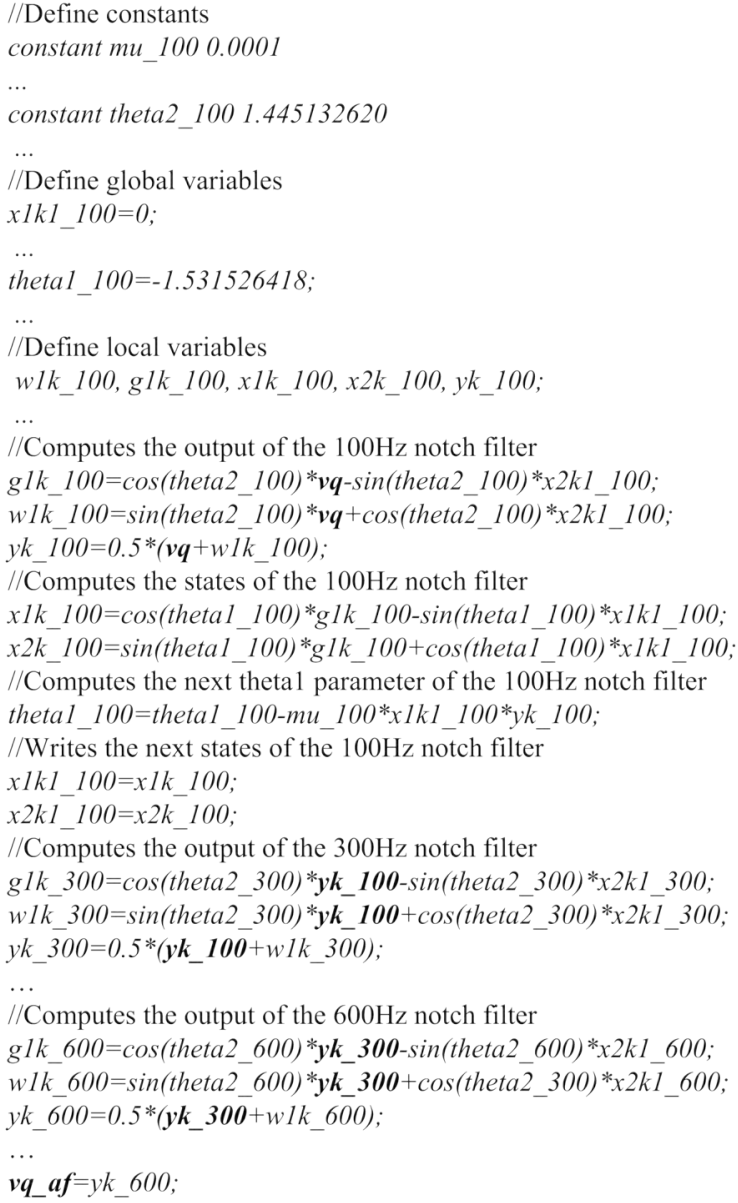

Fig. 21. FFT of a sinusoidal reference, $\sin \left(\hat{\theta}_{i}\right)$, obtained by means of the estimated phase, $\hat{\theta}_{i}$, of a ALSRF-PLL, for an unbalanced and distorted electric grid which frequency is $50 \mathrm{~Hz}$ (black-solid) and $55 \mathrm{~Hz}$ (grey-dotted).

[17] M. Karimi-Ghartemani and M. R. Iravani, "A method for synchronization of power electronic converters in polluted and variablefrequency environments," Power Systems, IEEE Transactions on, vol. 19, no. 3, 2004, pp. 1263-1270

[18] V. Kaura and V. Blasko, "Operation of a phase locked loop system under distorted utility conditions," Industry Applications, IEEE Transactions on, vol. 33, no. 1, 1997, pp. 58-63.

[19] "IEEE Recommended Practice for Utility Interface of Photovoltaic (PV) Systems," IEEE Std 929-2000, 2000, p. i.

[20] "IEEE Standard for Interconnecting Distributed Resources With Electric Power Systems," IEEE Std 1547-2003, 2003, pp. 0-16.

[21] L. N. Amuda, B. J. Cardoso Filho, S. M. Silva, S. R. Silva, and A. S. A. C. Diniz, "Wide bandwidth single and three-phase PLL structures for grid-tied PV systems," Photovoltaic Specialists Conference, 2000. B. J. Cardoso Filho, Ed. 2000, pp. 1660-1663.

[22] F. Liccardo, P. Marino, and G. Raimondo, "Robust and Fast ThreePhase PLL Tracking System," Industrial Electronics, IEEE Transactions on, vol. 58, no. 1, Jan.2011, pp. 221-231.

[23] F. D. Freijedo, J. Doval-Gandoy, O. Lopez, and E. Acha, "Tuning of Phase-Locked Loops for Power Converters Under Distorted Utility Conditions," Industry Applications, IEEE Transactions on, vol. 45, no. 6, Nov.2009, pp. 2039-2047.

[24] S. Hong-Seok, P. Hyun-Gyu, and N. Kwanghee, "An instantaneous phase angle detection algorithm under unbalanced line voltage condition,", 1 ed 1999, pp. 533-537.

[25] J. M. Guerrero, J. C. Vasquez, J. Matas, L. G. de Vicuna, and M. Castilla, "Hierarchical Control of Droop-Controlled AC and DC Microgrids-A General Approach Toward Standardization," Industrial Electronics, IEEE Transactions on, vol. 58, no. 1, Jan.2011, pp. 158172 
[26] J. C. Vasquez, J. M. Guerrero, A. Luna, P. Rodriguez, and R. Teodorescu, "Adaptive Droop Control Applied to Voltage-Source Inverters Operating in Grid-Connected and Islanded Modes," Industrial Electronics, IEEE Transactions on, vol. 56, no. 10, Oct.2009, pp. 40884096.

[27] S. Lisheng and M. L. Crow, "A novel PLL system based on adaptive resonant filter," 40th North American Power Symposium, 2008. NAPS '08., 2008, pp. 1-8.

[28] A. V. Timbus, M. Ciobotaru, R. Teodorescu, and F. Blaabjerg, "Adaptive resonant controller for grid-connected converters in distributed power generation systems," 21 Applied Power Electronics Conference and Exposition, APEC '06, 2006, p. 6.

[29] F. D. Freijedo, A. G. Yepes, O. pez, A. Vidal, and J. Doval-Gandoy, "Three-Phase PLLs With Fast Postfault Retracking and Steady-State Rejection of Voltage Unbalance and Harmonics by Means of Lead Compensation," Power Electronics, IEEE Transactions on, vol. 26, no. 1, Jan.2011, pp. 85-97.

[30] P. Rodriguez, J. Pou, J. Bergas, J. I. Candela, R. P. Burgos, and D. Boroyevich, "Decoupled Double Synchronous Reference Frame PLL for Power Converters Control," Power Electronics, IEEE Transactions on, vol. 22, no. 2, 2007, pp. 584-592.

[31] P. Rodriguez, A. Luna, I. Candela, R. Mujal, R. Teodorescu, and F. Blaabjerg, "Multi-Resonant Frequency-Locked Loop for Grid Synchronization of Power Converters Under Distorted Grid Conditions," Industrial Electronics, IEEE Transactions on, vol. 58, no. 1, 2011, pp. 127-138.

[32] P. A. Regalia, Adaptive IIR filtering in signal processing and control. Marcel Dekker, INC., 1995.

[33] N. Mohan, T. M. Undeland, and W. P. Robbins, Power Electronics. Converters, applications, and design., 3rd. ed. John Wiley \& Sons, Inc., 2003.

[34] M. H. Rashid, Power Electronics Handbook. Academic Press, 2007, pp. $1-1152$.

[35] A. Nehorai, "A minimal parameter adaptive notch filter with constrained poles and zeros," Acoustics, Speech and Signal Processing, IEEE Transactions on, vol. 33, no. 4, 1985, pp. 983-996.

[36] P. Stoica and A. Nehorai, "Performance analysis of an adaptive notch filter with constrained poles and zeros," Acoustics, Speech and Signal Processing, IEEE Transactions on, vol. 36, no. 6, 1988, pp. 911-919.

[37] S. Haykin, Adaptive filter theory. Prentice Hall, 2002.

[38] John G.Proakis and Dimitri G.Manolakis, Digital Signal Processing. Principles, Algorithms, and Applications., 4th ed. Pearson Prentice Hall, 2007.

[39] A. K. Kohli and D. K. Mehra, "Tracking of time-varying channels using two-step LMS-type adaptive algorithm," Signal Processing, IEEE Transactions on, vol. 54, no. 7, July2006, pp. 2606-2615.

[40] I. D. Schizas, G. Mateos, and G. B. Giannakis, "Distributed LMS for Consensus-Based In-Network Adaptive Processing," Signal Processing, IEEE Transactions on, vol. 57, no. 6, June2009, pp. 2365-2382.

[41] H. Byung-Moon, B. Byong-Yeul, and S. J. Ovaska, "Reference signal generator for active power filters using improved adaptive predictive filter," Industrial Electronics, IEEE Transactions on, vol. 52, no. 2, 2005, pp. 576-584.

[42] B. Singh and J. Solanki, "An Implementation of an Adaptive Control Algorithm for a Three-Phase Shunt Active Filter," Industrial Electronics, IEEE Transactions on, vol. 56, no. 8, Aug.2009, pp. 28112820.
[43] J. Arenas-Garcia, V. Gomez-Verdejo, and A. R. Figueiras-Vidal, "New algorithms for improved adaptive convex combination of LMS transversal filters," Instrumentation and Measurement, IEEE Transactions on, vol. 54, no. 6, Dec.2005, pp. 2239-2249.

[44] J. Glover, Jr., "Adaptive noise canceling applied to sinusoidal interferences," Acoustics, Speech and Signal Processing, IEEE Transactions on, vol. 25, no. 6, 1977, pp. 484-491.

[45] P. A. Regalia, "Stable and efficient lattice algorithms for adaptive IIR filtering," Signal Processing, IEEE Transactions on, vol. 40, no. 2, 1992, pp. 375-388.

[46] A. Gray, Jr. and J. Markel, "A normalized digital filter structure," Acoustics, Speech and Signal Processing, IEEE Transactions on, vol. 23, no. 3, June1975, pp. 268-277.

[47] P. P. Vaidyanathan and S. K. Mitra, "A unified structural interpretation of some well-known stability-test procedures for linear systems," Proceedings of the IEEE, vol. 75, no. 4, Apr.1987, pp. 478-497.

[48] F. Gonzalez-Espin, E. Figueres, G. Garcera, R. Gonzalez-Medina, and M. Pascual, "Measurement of the Loop Gain Frequency Response of Digitally Controlled Power Converters," Industrial Electronics, IEEE Transactions on, vol. 57, no. 8, Aug.2010, pp. 2785-2796.

[49] Texas Instruments, "RTDX 2.0 Reference Guide," 2010.

[50] "Características de la tensión suministrada por las redes generales de distribución," UNE-EN 50160, 2011.

\section{Fran González-Espín}

Emilio Figueres

\author{
Gabriel Garcerá
}

